\title{
Greater lifestyle engagement is associated with better cognitive resilience
}

G. Sophia Borgeest ${ }^{1 *}$, Richard N. Henson ${ }^{1}$, Meredith Shafto ${ }^{2}$, David Samu², Cam$\mathrm{CAN}^{3}$ \& Rogier A. Kievit ${ }^{1}$

*Corresponding author: sophia.borgeest@mrc-cbu.cam.ac.uk

1. MRC Cognition and Brain Sciences Unit, University of Cambridge

2. Department of Psychology, University of Cambridge

3. Cambridge Centre for Ageing and Neuroscience (Cam-CAN), University of Cambridge and MRC Cognition and Brain Sciences Unit, Cambridge CB2 3EB, United Kingdom

Author note: code of all analyses and the covariance matrix are available here:

https://osf.io/7n4d6/ 


\section{Abstract}

Previous evidence suggests that modifiable lifestyle factors, such as engagement in leisure activities, might slow the age-related decline of cognitive functions. Less is known, however, about which aspects of lifestyle might be particularly beneficial to healthy cognitive ageing, and whether they are associated with distinct cognitive domains (e.g. fluid and crystallized abilities) differentially. We investigated these questions in the cross-sectional Cambridge Centre for Ageing and Neuroscience (Cam-CAN) data ( $N=708$, age 18-88), using data-driven exploratory structural equation modelling, confirmatory factor analyses, and age-residualized measures of cognitive differences across the lifespan. Specifically, we assessed the relative associations of the following five lifestyle factors on age-related differences of fluid and crystallized resilience: education/SES, physical health, mental health, social engagement, and intellectual engagement. We found that higher education, better physical and mental health, more social engagement and a greater degree of intellectual engagement were each individually correlated with better fluid and crystallized cognitive resilience. A joint path model of all lifestyle factors on crystallized and fluid resilience, which allowed a simultaneous assessment of the lifestyle domains, showed that physical health, social and intellectual engagement and education/SES explained unique, complementary variance, but mental health did not make significant contributions above and beyond the other four lifestyle factors and age. The total variance explained for fluid resilience was $14 \%$ and $16 \%$ for crystallized resilience. Our results are compatible with the hypothesis that intellectually and physically challenging as well as socially engaging activities are associated with better crystallized and fluid performance across the lifespan. 


\section{Research Highlights}

1. Higher education/SES, better physical and mental health, more social engagement and a greater degree of intellectual engagement are all individually associated with better cognitive health across the lifespan.

2. When all five lifestyle factors were assessed simultaneously, we found that physical health and social as well as intellectual engagement are independently associated with individual differences in cognitive health, above and beyond the effect of education/SES. Mental health makes no additional independent contributions.

3. Education/SES, physical health, intellectual engagement and social engagement show similar patterns with crystallized and fluid cognitive resilience, suggesting that the associations between lifestyle engagement and cognition are global rather than cognitive-domain specific.

4. Age-corrected residuals as a proxy of cognitive health across the lifespan may be a useful tool for future cross-sectional studies comparing different age groups. 


\section{Introduction}

\section{Lifestyle and Healthy Ageing}

Cognitive abilities are known to decline with age $(1,2)$. The extent to which leading an active lifestyle can slow down this decline has been debated in the literature, with some studies associating physical, intellectual and social activities with cognitive and neural health while others did not find such relationships (3-5). Here, we address three open questions regarding the possible associations between lifestyle and cognitive resilience.

First, the relationship between lifestyle and cognition has predominantly been studied by assessing lifestyle activities separately (e.g. by focusing on physical health or social engagement, but rarely both). Previous studies which have assessed various aspects of lifestyle have tended to rely on separate linear regressions (6-8), mediation analyses (9) or sum scores $(10,11)$ for their analyses, limiting the extent to which possible complementary benefits of lifestyle can be detected. Thus, unless these factors are analysed conceptually and mathematically simultaneously, it remains an open question as to whether individual lifestyle factors will 'sum up' to demonstrate incremental benefits, or rather be redundantly associated with better outcomes (see also Kremen et al., 2019 (12)). Our structural equation modelling approach, outlined below, addresses this gap in the literature by offering several benefits compared to previous approaches. First, we model both cognitive and lifestyle factors as latent variables, which abstracts away from individual variables whilst reducing measurement error associated with simple sum scores. Latent variables widen the interpretability of lifestyle-cognition associations to activity types (for instance 'social activity') instead of individual activities (e.g. 'attending church'). Moreover, we model 
multiple lifestyle factors within the same large healthy population, allowing us to compare effect sizes. Most uniquely, our structural model captures the simultaneous effect of multiple latent lifestyle factors on cognitive lifespan differences, allowing us to investigate whether associations of specific lifestyle domains remain after taking into account distinct, but correlated, lifestyle factors.

Second, little is known about whether different aspects of cognition are associated differently with lifestyle engagement. Following a distinction first made by Cattell (1943), cognitive abilities can, at a high level, their broadest level, often grouped into fluid and crystallized abilities. Fluid intelligence refers to the ability to solve novel problems in the absence of taskspecific knowledge or experience. It predicts important life outcomes such as expected income or work performance (14). Age produces a marked impairment in fluid intelligence; a decline that begins in early adulthood (see Schaie (1994) for a review (15)). Moreover, recent findings have demonstrated that individual declines in fluid intelligence are highly correlated with individual declines in the ability to live and function independently (16). Crystallized intelligence, on the other hand, refers to acquired knowledge about the world (such as vocabulary) and shows more modest changes with age than fluid intelligence, typically declining only in old age (i.e. after the late sixties; $2,6,8,9$ ). One open question, addressed here, is whether crystallized and fluid abilities, known to differ in their lifespan trajectories, also benefit differently from measures associated with better cognitive ageing.

Third, it has been difficult to reliably identify those lifestyle activities that enhance cognitive reserve as is demonstrated by the considerable heterogeneity of findings in the literature (19). This is likely to be due to at least two reasons. One concerns the large diversity of 
lifestyle variables that have been assessed, with studies differing on the types of activities that make up, say, social engagement. A second explanation is the variable and often imprecise definition of 'healthy ageing' in cross-sectional studies. For instance, many crosssectional studies rely on classifying groups of people according to their absolute performance on cognitive tests (e.g., 27,28). In such an approach, older individuals who score an arbitrary number of standard deviations above a task mean are labelled 'healthy', 'successful', or in some cases even 'super' agers (22-24), while those beneath this cut-off point are considered to age only 'normally' or 'poorly'. Here, we conceptualize 'healthy aging' as a matter of 'resilience' by using a simple continuous age-adjusted measure, which we describe in more detail below. This measure avoids the drawbacks of arbitrary statistical cut-off points and dichotomisation (25), and allows for a natural conceptualization of 'resilient aging', namely whether an individual is performing better or worse than would be expected at her age.

\section{The present study}

Although enhanced physical, mental and social lifestyle components have all been associated with healthier cognition, these effects have predominantly been investigated in isolation (e.g. by looking at physical health or social engagement, but rarely both). A simultaneous analysis of these associations would shed more light on the possible complementary benefits of various aspects of people's lives. Moreover, understanding if lifestyle is associated differently with crystallised and fluid cognition is important in order to guide effective interventions. We therefore investigated the simultaneous associations between various aspects of lifestyle and both fluid and crystallized resilience. We used a large $(N=708)$ age-heterogeneous population-based sample from the Cambridge Centre for Ageing and Neuroscience (CamCAN), employing age-residualized measures of cognition, data-driven exploratory structural 
equation modelling and confirmatory factor analysis. Note that as our data are crosssectional rather than longitudinal or intervention-based, we cannot resolve whether there are direct (causal) associations, nor rule out reverse causation, nor assess whether there are third variables such as genetic influences which induce shared covariance (26). These limitations are further discussed in the discussion.

\section{Methods}

\section{Participants}

Participants were drawn from the Stage 2 sample of the Cambridge Centre for Ageing and Neuroscience (Cam-CAN) dataset, described in more detail elsewhere $(27,28)$. Exclusion criteria included low Mini Mental State Exam (MMSE; 24 or lower; (29)), poor hearing (failing to hear 35dB at $1000 \mathrm{~Hz}$ in either ear), poor vision (below 20/50 on Snellen test; (30), poor English knowledge (non-native or non-bilingual English speakers), self-reported substance abuse, and serious health conditions that affect participation (e.g. self-reported major psychiatric conditions, current chemo/radiotherapy, or a history of stroke). 708 people (359 women, 349 men) were recruited, including approximately 100 people in each decile (age range 18-88, $M=53.4, S D=18.62$ ). Participants provided a wide range of cognitive measures and questionnaire data, summarized below and in Table 1. Ethical approval for the study was obtained from the Cambridgeshire 2 (now East of England-Cambridge Central) Research Ethics Committee. Participants gave full informed consent. The raw data can be acquired by applying for access through the Cam-CAN data portal (https://camcan.mrc-cbu.cam.ac.uk/). All code used in the paper is available via this repository: https://osf.io/7n4d6/ 


\section{$\underline{\text { Cognitive Variables }}$}

13 cognitive tasks were used to assess five broad cognitive domains, which are summarized

in Table 1 (for more detail, see $(27,28)$ ). The cognitive domains assessed were executive

functions, memory, language functions, motor and action function and emotional processing.

Table 1: description of cognitive behavioural tasks

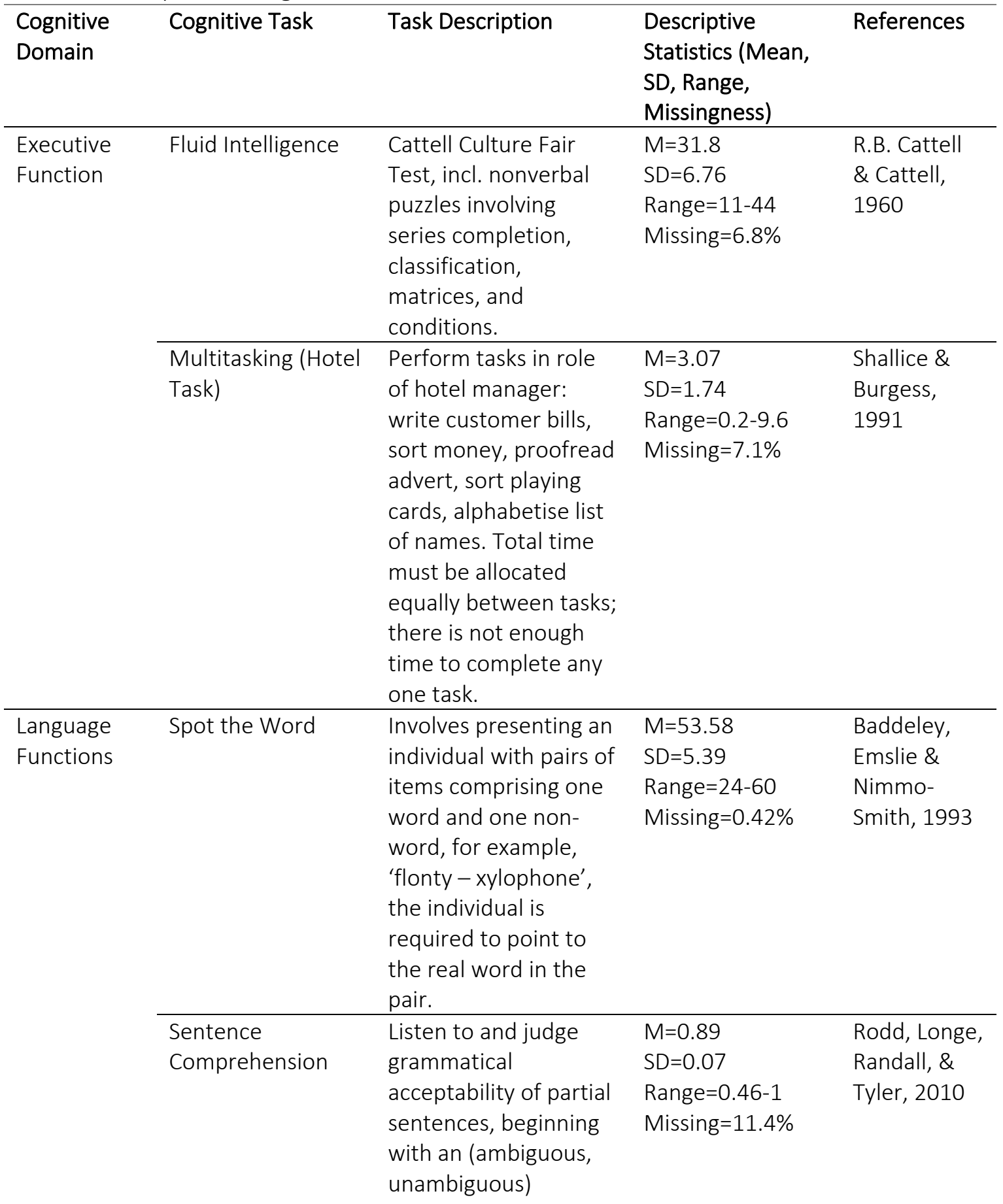




\begin{tabular}{|c|c|c|c|c|}
\hline & & \multicolumn{3}{|l|}{$\begin{array}{l}\text { sentence stem (e.g., } \\
\text { "Tom noticed that } \\
\text { landing planes...") } \\
\text { followed by a } \\
\text { disambiguating } \\
\text { continuation word } \\
\text { (e.g., "are") in a } \\
\text { different voice. } \\
\text { Ambiguity is either } \\
\text { semantic or syntactic, } \\
\text { with empirically } \\
\text { determined dominant } \\
\text { and subordinate } \\
\text { interpretations }\end{array}$} \\
\hline & $\begin{array}{l}\text { Picture-Picture } \\
\text { Priming }\end{array}$ & $\begin{array}{l}\text { Name the pictured } \\
\text { object presented } \\
\text { alone (baseline), then } \\
\text { when preceded by a } \\
\text { prime object that is } \\
\text { phonologically related } \\
\text { (one, two initial } \\
\text { phonemes), } \\
\text { semantically related } \\
\text { (low, high } \\
\text { relatedness), or } \\
\text { unrelated }\end{array}$ & $\begin{array}{l}\mathrm{M}=0.78 \\
\mathrm{SD}=0.09 \\
\text { Range=0.5-0.94 } \\
\text { Missing=8.3\% }\end{array}$ & $\begin{array}{l}\text { Clarke, } \\
\text { Taylor, } \\
\text { Devereux, } \\
\text { Randall, \& } \\
\text { Tyler, } 2013\end{array}$ \\
\hline & Verbal Fluency & $\begin{array}{l}\text { Mean of Letter } \\
\text { (phonemic) fluency } \\
\text { and animal (semantic) } \\
\text { fluency task. For } \\
\text { phonemic fluency task, } \\
\text { participants have } 1 \\
\text { min to generate as } \\
\text { many words as } \\
\text { possible beginning } \\
\text { with the letter 'p'. For } \\
\text { semantic fluency task, } \\
\text { participants have } 1 \\
\text { min to generate as } \\
\text { many words as } \\
\text { possible in the } \\
\text { category 'animals'. }\end{array}$ & $\begin{array}{l}M=20.56, \\
S D=5.34 \\
\text { Range=6-37.5 } \\
\text { Missing=0.28\% }\end{array}$ & $\begin{array}{l}\text { Lezak, } \\
\text { Muriel, \& } \\
\text { Deutsch, } \\
1995\end{array}$ \\
\hline & $\begin{array}{l}\text { Proverb } \\
\text { Comprehension }\end{array}$ & $\begin{array}{l}\text { Read and interpret } \\
\text { three English } \\
\text { proverbs. }\end{array}$ & $\begin{array}{l}M=4.53 \\
S D=1.63 \\
\text { Range }=0-6 \\
\text { Missing }=7.5 \%\end{array}$ & $\begin{array}{l}\text { Hodges, } \\
1994\end{array}$ \\
\hline $\begin{array}{l}\text { Emotional } \\
\text { Processing }\end{array}$ & Face Recognition & $\begin{array}{l}\text { Given a target image } \\
\text { of a face, identify } \\
\text { same individual in an } \\
\text { array of } 6 \text { face images } \\
\text { (with possible changes }\end{array}$ & $\begin{array}{l}M=22.88 \\
S D=2.36 \\
\text { Range }=14-27 \\
\text { Missing=7.2\% }\end{array}$ & $\begin{array}{l}\text { Benton, } \\
1994\end{array}$ \\
\hline
\end{tabular}




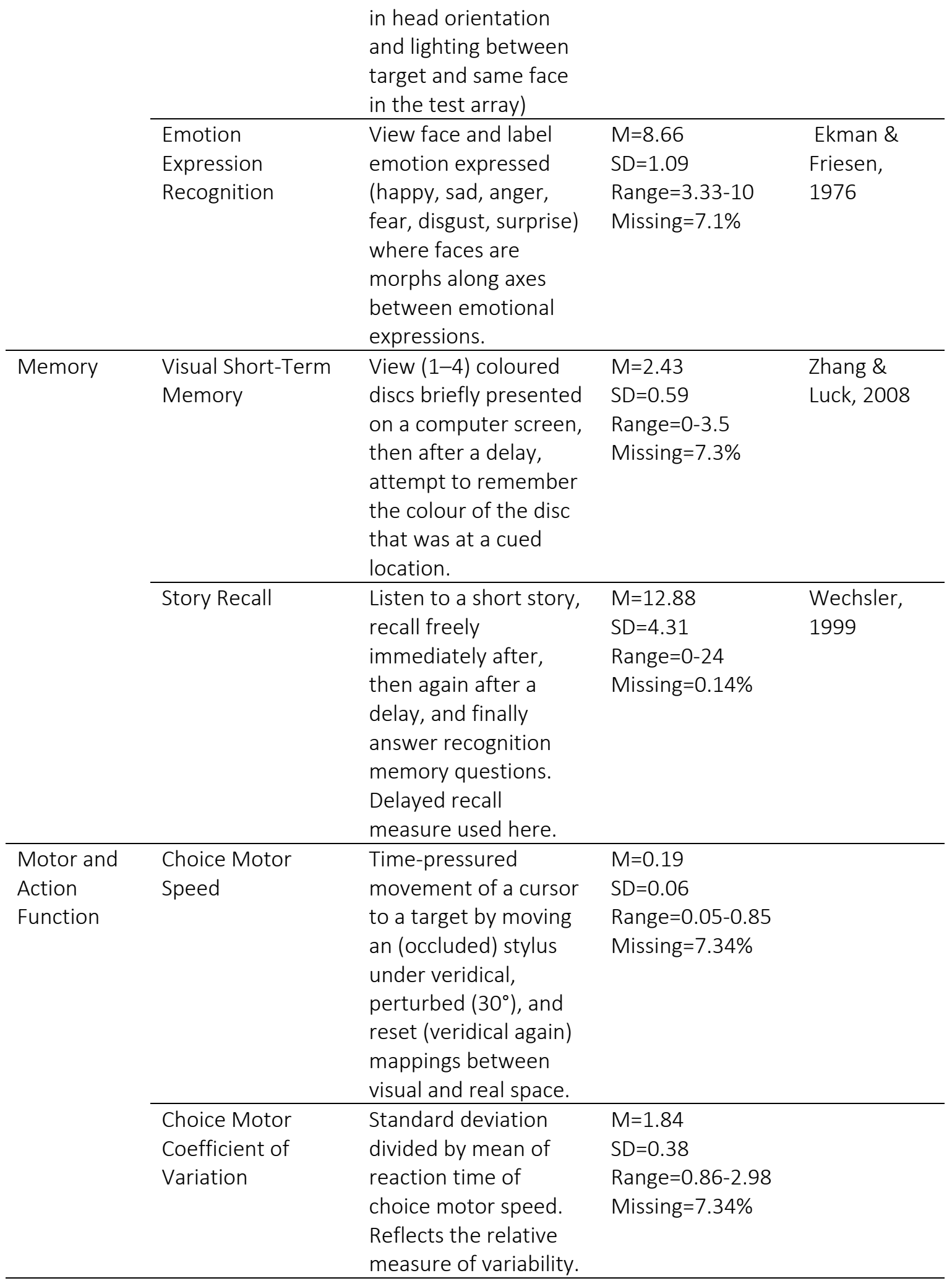




\section{Lifestyle Variables}

We included a broad set of 23 lifestyle measures from the Cam-CAN dataset, which were collected via a series of different questionnaires, summarized in Table 2. Eight lifestyle variables were obtained during the Home Interview, an extensive face-to-face interview conducted at Stage 1 of Cam-CAN data collection. The remaining variables were obtained during Stage 2. Measures of physical activity, depression and sleep were assessed via the physical activity energy expenditure (PAEE) questionnaire, the Hospital Anxiety and Depression Scale (HADS; (31) and the Pittsburgh Sleep Quality Index (PSQI; (32)), respectively. The remaining 12 lifestyle variables were taken from the Lifetime of Experiences Questionnaire (LEQ; (33)), which measures a broad range of cognitively stimulating experiences and activities during three life phases: youth, 13-29 years; mid-life, 30-64 years; and late-life, 65 years onwards. Within each phase, further details about activities "specific" to that time of life (e.g. education in youth) were solicited, as well as "non-specific" activities applicable to any phase (e.g. socialising). The LEQ therefore provides information about current life experiences for all participants, as well as retrospective information about previous life experience for participants in their mid-and late-life phases. Usually, this information is reflected in one specific and one non-specific sum score for each stage of life. In this study, however, we focused on a more fine-grained and consistent (across our participants) scoring procedure. First, we define our measure of education as the young-age specific score, derived from the UK's National Career Service categories and multiplied by number of years at each category. Second, we included only current non-specific activities depending on the age of the individual, as we wanted to focus on contemporaneous activities, and allow consistent data across our full age range (34). Third, as our core goal of this study was to understand which kind of lifestyle activity is most strongly associated with 
age-related cognitive differences, we obtained separate scores for a subset (7) of the nonspecific questions, rather than calculating the usual sum-score. As these seven questions (see Table 2) cover a range of lifestyle activities, individual scores for each question gave us more precision in determining their covariance to other lifestyle factors. Non-specific activities were assessed through the same seven questions during youth, mid-life and late-life, addressing participation in i) travel, ii) social outings, iii) playing a musical instrument, iv) artistic pastimes, v) physical activity (mild, moderate, vigorous), vi) reading, vii) learning or speaking a second language. In addition, participants were asked whether their typical day included any of the following four activities: i) internet use, ii) strategic games (e.g. chess, bridge, cards), iii) prayer/religious activity, iv) brain training games. All non-specific scores were scaled to a score from 0-5.

Table 2: Description of lifestyle variables. Note: The grouping into 'lifestyle factors' is the result of the factor analysis outlined in more detail below.

\begin{tabular}{|c|c|c|c|c|}
\hline $\begin{array}{l}\text { Lifestyle } \\
\text { Factor }\end{array}$ & Variable & Description/Question & Descriptive Statistics & Reference \\
\hline \multirow[t]{5}{*}{ Education/SES } & Income & $\begin{array}{l}\text { What is the average total } \\
\text { income before tax received } \\
\text { by your household? (1-5) }\end{array}$ & $\begin{array}{l}\mathrm{M}=2.83 \\
\mathrm{SD}=1.49 \\
\text { Range }=1-6 \\
\text { Missing=0.14\% }\end{array}$ & $\mathrm{HI}^{1}$ \\
\hline & $\begin{array}{l}\text { Smoking } \\
\text { habits }\end{array}$ & $\begin{array}{l}\text { category of smoking based } \\
\text { on self-report questions (1- } \\
\text { 3) }\end{array}$ & $\begin{array}{l}M=1.03 \\
S D=0.97 \\
\text { Range }=0-3 \\
\text { Missing }=1.4 \%\end{array}$ & $\mathrm{HI}$ \\
\hline & $\begin{array}{l}\text { TV } \\
\text { watching** }\end{array}$ & $\begin{array}{l}\text { How much TV do you watch } \\
\text { per week? }\end{array}$ & $\begin{array}{l}M=2.2 \\
\mathrm{SD}=1.47 \\
\text { Range }=0-7 \\
\text { Missing=61.9\% }\end{array}$ & $\mathrm{HI}$ \\
\hline & $\begin{array}{l}\text { Body Mass } \\
\text { Index (BMI) }\end{array}$ & Weight (kg) / Height ${ }^{2}\left(\mathrm{~m}^{2}\right)$ & $\begin{array}{l}M=25.78 \\
S D=4.59 \\
\text { Range }=16.75-48.32 \\
\text { Missing }=17.2 \%\end{array}$ & $\mathrm{HI}$ \\
\hline & Travel & $\begin{array}{l}\text { Did you travel to any of the } \\
\text { following continents } \\
\text { between the ages of } 13-30 \\
\text { years? } \\
\text { ( } 9 \text { options available) }\end{array}$ & $\begin{array}{l}\mathrm{M}=2.3 \\
\mathrm{SD}=1.25 \\
\text { Range }=0-5 \\
\text { Missing }=12.01 \%\end{array}$ & $\mathrm{LEQ}^{2}$ \\
\hline
\end{tabular}




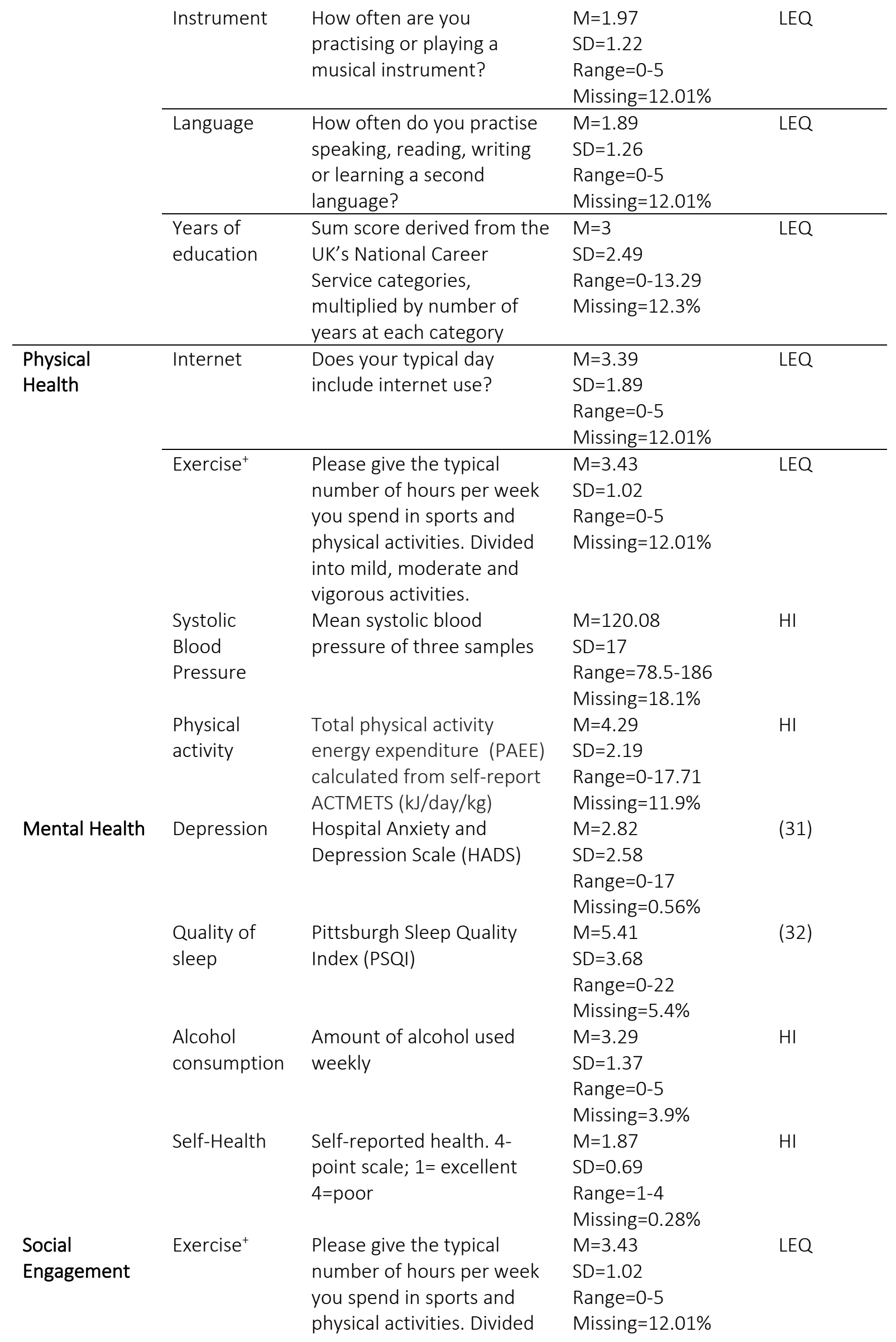




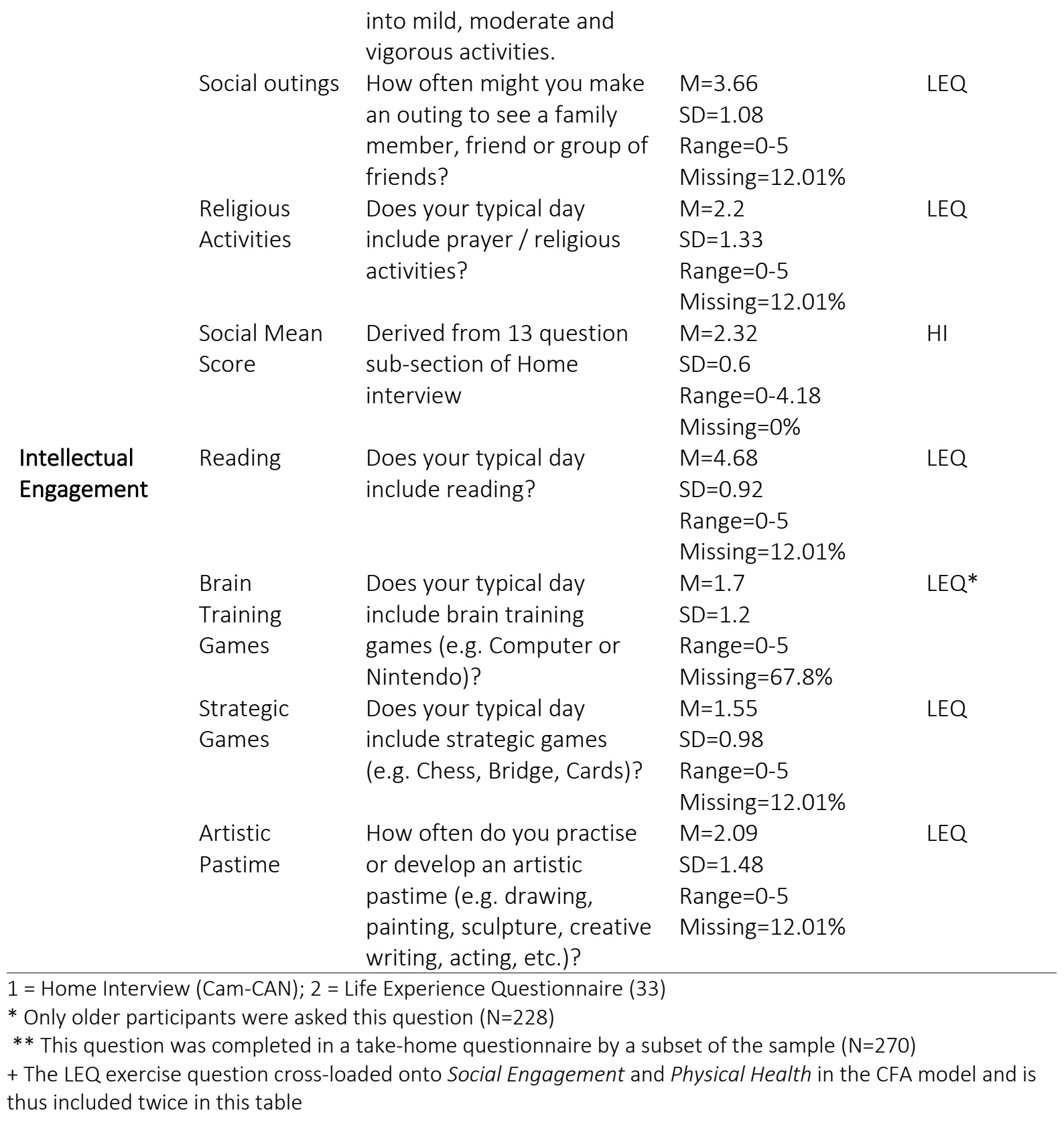

\section{$\underline{\text { Exploratory Structural Equation Model (ESEM) }}$}

In order to obtain a data-driven categorization of our cognitive and lifestyle variables, we used a relatively novel technique called exploratory structural equation modelling (ESEM; see (35)). ESEM integrates confirmatory factor analysis (CFA) and structural equation modelling (SEM) to provide confirmatory tests of a priori factor structures. ESEM can be distinguished from CFA mainly in that the former does not require the researcher to define an a-priori 
factor structure. Based on theory, CFA measurement models specify a number of factor loadings fixed at zero to reflect a hypothesis that only certain factors influence certain factor indicators. The CFA approach of fixing many or all cross-loadings at zero may force a researcher to specify a more parsimonious model than is suitable for the data. Because of this, models often do not fit the data well and there is a tendency to rely on extensive model modification to find a well-fitting model. A commonly used alternative to CFA is Exploratory Factor Analysis (EFA), which solves some of CFA's challenges in situations of limited measurement knowledge of the researcher and / or a more complex measurement structure. However, EFA cannot be performed while allowing correlated residuals, and it assumes that all measured variables are related to every latent variable. For these reasons, researchers often opt for an ad-hoc procedure that mimics the EFA factor definitions in a SEM model with a CFA measurement specification. This EFA-to-CFA conversion has been shown to be challenging, and can lead to mis-specified models. The main advantage of the ESEM model over other modelling practices is that ESEM incorporates seamlessly the EFA and SEM models. ESEM integrates EFA into SEM (which otherwise relies on CFA measurement models) by estimating the measurement and structural model parts simultaneously. The key difference between ESEM and Principal Component Analysis (PCA) is that the latter is a linear combination of variables, whereas the former (as it relies on factor analyses) is a latent variable measurement model. We used the package psych (version 1.7.8; 41) in R-Studio 1.0.153 (R version 3.4.2).

\section{$\underline{\text { Resilient cognitive ageing }}$}

After computing the best age-related trajectories, we computed indices of resilient ageing in each domain. We define resilient ageing by separately regressing fluid and crystallized factor 
scores on age, and retaining the residual score for each participant and factor. Each residual score reflects the difference between the participants' observed and her age-predicted factor scores. Because the residuals were obtained from a curve reflecting age-related differences, they do not represent the difference between a participant's score and the overall mean, but rather of the mean expected for the participant's age (thus, the age-adjusted mean). Although these scores will still correlate with raw scores within each domain, these residuals adjust for age-expected declines, allowing, for example, an 80-year old person with a relatively low absolute score to be considered (more) resilient than a younger individual with a higher score. Similar measures have been proposed to quantify 'brain age' (37) and resilience in the aftermath of adverse childhood experiences (38). To check that the correlation between the raw scores and residuals did not vary with age, we conducted a median split analysis. The residuals serve as our measure of healthy ageing in further analyses.

\section{Confirmatory Factor Analysis (CFA)}

In the second step of our analyses, we used a set of simpler confirmatory factor analyses (CFA models) to a) achieve stable model estimation and b) facilitate detailed model comparisons. CFA is a multivariate statistical procedure that allows the researcher to specify the number of latent and observed constructs in order to test how well the former are captured by the latter. Translating our ESEM solutions to CFA models allowed us to formally test more parsimonious models that remove negligible cross-loadings, and to assess overall model fit using a more conventional range of model fit indices. Although such a two-step procedure is ideally performed on two independent subsamples of the data, this was not feasible given the necessity to balance between model complexity, sample size and stable 
convergence. To decrease the risk of overfitting, we constrained the range of unnecessary cross-loadings to zero. Although one-step, or factor score regression approaches (39), are generally considered preferable, challenges with convergence and model estimation precluded such approaches here. As such, we specified CFA's separately for each domain and used estimated factor scores in the second stage. All models were fit using Lavaan 0.6-1.1203 version (40). Prior to model fitting, one variable with very large variance (Multitasking, measured in milliseconds) was rescaled by dividing by 100 to avoid convergence problems. All models were fit using maximum likelihood estimation with robust (Huber-White) standard errors and a scaled chi square test statistic (40). Missing data, reported in Tables 1 and 2, were accounted for using Full Information Maximum Likelihood method in Lavaan, which allowed us to estimate factor scores for all individuals, including those with partially missing data and yields unbiased estimates under the assumption of missing at random or missing completely at random (41).

Model fit was inspected using the chi-square test, the Root Mean Square Error of Approximation (RMSEA) and its confidence interval, the Comparative Fit Index (CFI) and the Standardized Root Mean Square Residual (SRMR). Good fit was defined as approximately RMSEA $<0.05$, CFI $>0.97$ and SRMR $<0.05$, acceptable fit as approximately RMSEA $=0.08-$ $0.05, \mathrm{CFI}=0.95-0.97, \mathrm{SRMR}=0.05-0.1(42)$. To examine the robustness of the CFA model we refit the subsequent path model in a Bayesian model selection framework (43) using Bayesian regression.

Finally, we examined the degree to which lifestyle factors made specific contributions to fluid versus crystallized cognitive differences. To do so, we refit the models while imposing equality constraints on the lifestyle paths. In other words, we compared a model where the 
effects of lifestyle factors are estimated individually for each of the two cognitive domains, to a more parsimonious model where the path coefficients are assumed to be identical for fluid and crystallized resilient ageing. If the effects of lifestyle factors are equal for both cognitive domains, then one would expect an equality constrained model (where the effects of lifestyle factors on cognitive domains are presumed to be equal) to fit better. However, if certain lifestyle factors have stronger, or weaker, effects on each domain, then one would expect a model that estimates all structural paths freely to fit better.

\section{Exploratory Analyses}

We performed a series of exploratory analyses to assess the presence of i) an interaction effect of age and lifestyle using a median split and ii) sex effects. 


\section{Results}

\section{Exploratory Structural Equation Model}

The sample-size adjusted BIC scores are shown in Figure 1 (the first number in each model name refers to the number of cognitive variables, and the second number refers to the number of lifestyle variables). The ESEM analyses revealed that, generally, two- and three factor models of cognitive abilities fit the data substantially better than a one factor model. The three factor solutions had marginally better fit than the two factor solutions (e.g., $\triangle \mathrm{BIC}=$ 13.55 for the 2_5 versus 3_5 model). However, we opted for a two factor solution for theoretical reasons, as the two factor solution closely resembled the canonical distinction between fluid and crystallized abilities, in line with Cattell (13) and a large body of body of work on cognitive aging (44-46). Moreover, we note that, in the two factor cognitive model, although the strongest factor loading on the first 'fluid' factor is the Cattell test, it includes a relatively large, and broad, number of cognitive abilities, several of which are beyond the traditional remit of pure fluid intelligence (17). 


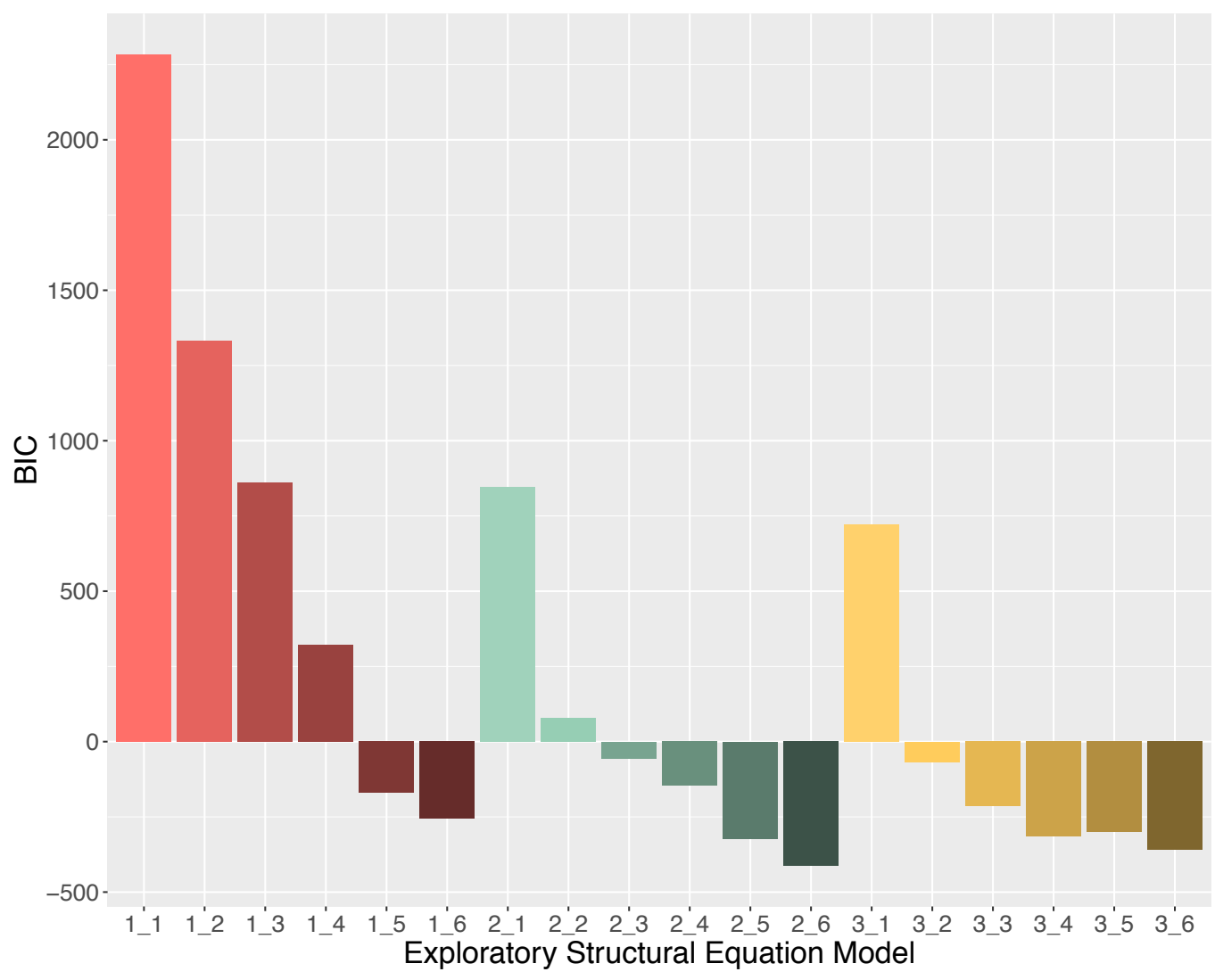

Figure 1. Exploratory Structural Equation model results. Y-axis reflects Bayesian Information Criterion (BIC) measure of model fit; $X$-axis labels consist of two digits separated by an underscore (e.g. 2_4), where the first refers to the number of cognitive latent variables, and the second to the number of lifestyle latent variables. Model 2_6 has the best overall fit, then Model 3_6; however, Model 2_5 was selected for further examination due difficulties interpreting the sixth lifestyle factor in the 2_6 and 3_6 models.

With regards to the lifestyle variables, a purely data driven solution suggested a six-factor lifestyle model (e.g., $\triangle \mathrm{BIC}=86.54$ for the 2_5 vs 2_6 model). However, closer inspection showed that the sixth factor induced a range of hard to interpret cross-loadings, suggesting that it (in both the two- and the three- cognitive factor solution) did not contain information that could be distinguished from the other factors in a meaningful way. For reasons of parsimony and theoretical interpretability, we therefore selected the five-factor solution for further examination. 


\section{CFA: Cognitive Model}

First, we fit the cognitive data with a two-factor model that mirrors the canonical distinction between crystallized and fluid abilities (13). One notable exception was that this model required a single data-driven cross-loading for the sentence comprehension task, which may reflect the nature of the task as a combination of being knowledge-based (whether a sentence is grammatical) and benefiting from fluid ability. This cognitive measurement model, shown in Figure 2A, fit the data well: $\chi^{2}=233.87(\mathrm{~N}=708), \mathrm{df}=63, \mathrm{p}<0.001, \mathrm{RMSEA}=$ $0.057[0.0490 .066], C F I=0.93, S R M R=0.048$, suggesting that the cognitive data were well captured by a two-factor model.

Next, we extracted factor scores for all individuals to examine the most appropriate lifespan trajectory for each domain (linear or quadratic). As expected, fluid and crystallized factors showed different lifespan patterns. Scores on the fluid latent variable showed a strong agerelated decline, with a modest acceleration of this decline in old age (Figure 2B), consistent with the best-fitting model including a quadratic component $\left(\mathrm{BIC}_{\text {Quadr }}=1391.15, \mathrm{BIC}\right.$ Lin $=$ 1458.09, $\mathrm{BIC}$ cubic $=1393.17)$. Scores on the crystallized latent variable were less variable across the lifespan, with a slight increase until middle age but suggestion of decline in old age (Figure $2 \mathrm{C})$, again consistent with a quadratic component $\left(\mathrm{BIC}_{\text {Quadr }}=1676.27, \mathrm{BIC}_{\mathrm{Lin}}=\right.$ 1696.91, BIC Cubic $=1678.06)$. 
A)

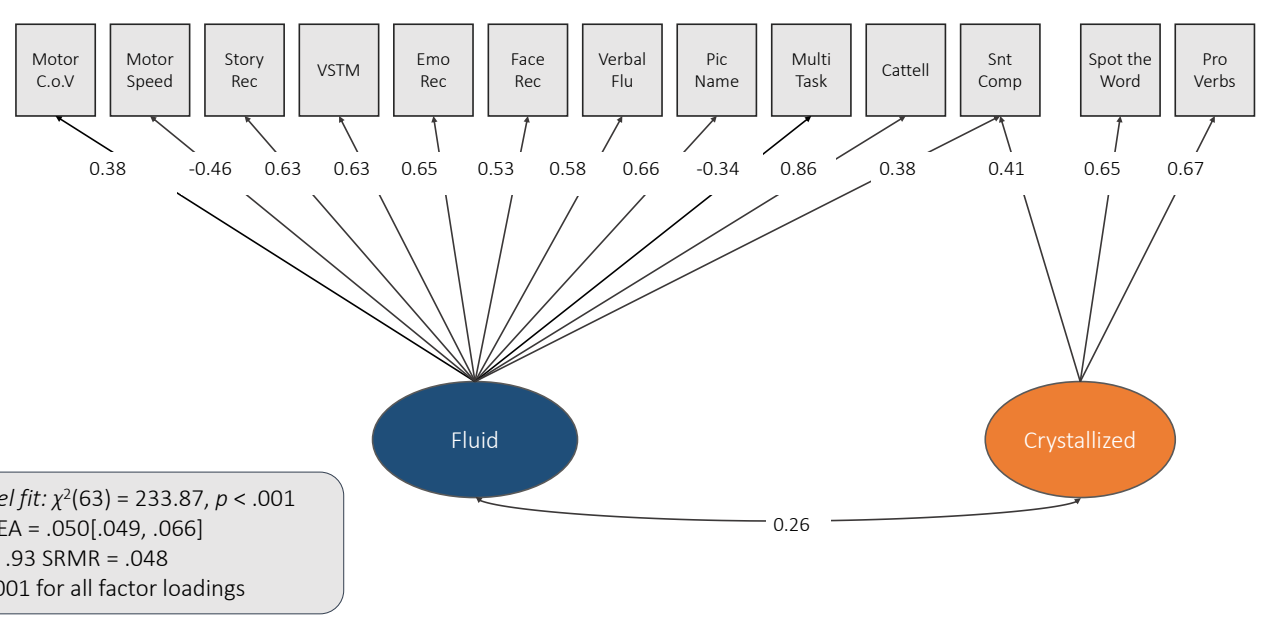

B)

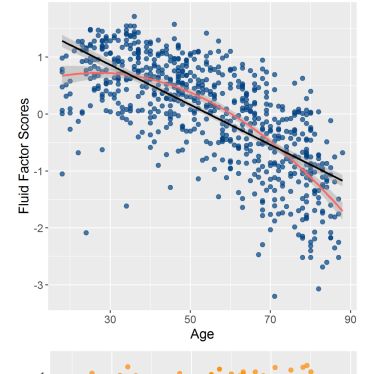

C)

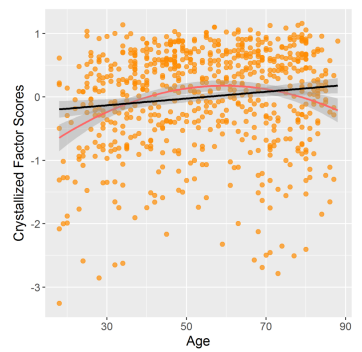

Figure 2. A) Cognitive CFA. For multitasking and motor speed, lower scores indicate better performance (hence the negative factor loadings). B) Fluid factor scores for each participant. Fluid abilities decline with age. C) Crystallized factor scores for each participant; crystallized abilities show slight increase and then decrease. All parameters shown are fully standardized.

\section{$\underline{\text { Resilient cognitive ageing }}$}

Fluid and crystallized measures of resilient ageing (shown in Figure 3) were significantly positively correlated (Pearson's $r=0.59$ [0.53 0.63], $\mathrm{df}=706, p=<0.001$ ). The median (age 55) split analysis showed that the Gf-Gc correlation of residuals did not differ significantly for the two age groups $(z=0.8, p=0.42)$.

A)

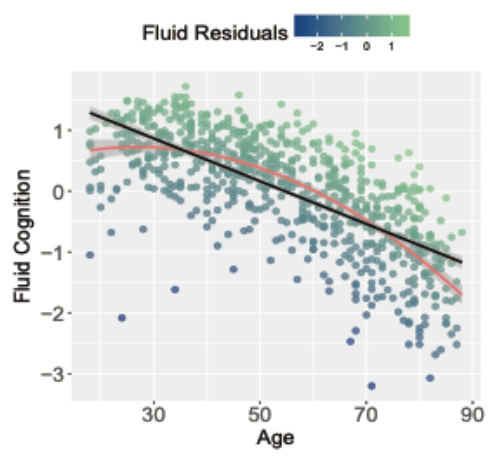

B)

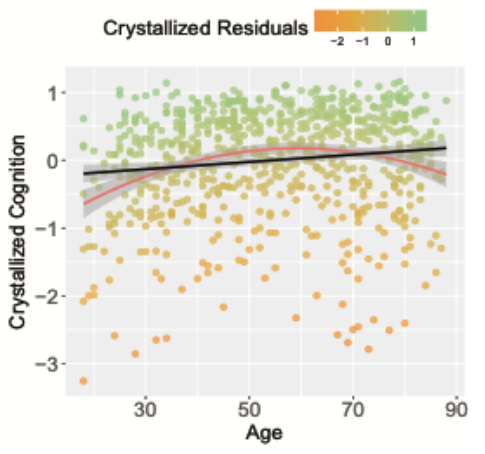

C)

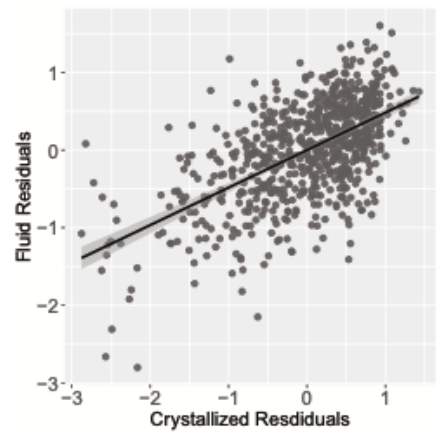


Figure 3. Residuals as measure of healthy cognitive ageing. A) Crystallized residuals, B) fluid residuals, C) correlation between crystallized and fluid residuals; $r(706)=.59, p<.001$.

\section{CFA: Lifestyle Model}

Next, we examined the lifestyle domains in more detail. To do so, we used the ESEM results to specify a simpler (fewer cross-loadings) CFA that captured the observed variables across five latent factors (Figure 4). Based on the pattern of loadings, we refer to these five latent variables as follows: i) Education/Socio-Economic Status (SES), ii) Physical Health, iii) Mental Health, iv) Social Engagement, v) Intellectual Engagement. Education/SES consisted of eight variables, namely years of education, income, language, travel, smoking, TV watching and instrument playing. Physical Health consisted of systolic blood pressure, internet usage, the PAEE score and the LEQ exercise score. Mental health was captured by alcohol usage, depression, self-reported health and sleep quality. The factor loadings of Intellectual Engagement were reading, brain training games, strategic games, Sudoku/Crossword and the degree of engagement in artistic pastime. Lastly, Social Engagement was characterized by religious activity, social outing, the social activity score from the Home Interview and the LEQ physical exercise score. Note, the labels of the factors are for convenience and based on the strongest loadings - some include factor loadings on variables are not canonically associated with the construct. As was the case for the cognitive CFA, this model therefore required one data-driven cross-loading for the LEQ exercise variable, which may reflect that fact that many physical activities (e.g. basketball, hiking) include significant social aspects. The model showed adequate fit to the data in most respects: $\chi^{2}(241)=747.69(N=708), p<0.001$, RMSEA $=0.055$ [0.050 0.059], $C F I=0.720, S R M R=0.060$, although the $C F I$ is lower than preferable, likely due to the modest factor loadings of some variables. Given the nature of the observed scores (see Table 2), higher scores in Social and Intellectual Engagement and 
SES/Education reflect more engagement and increased socioeconomic status, respectively. In contrast, higher scores in the Physical Health and Mental Health factors, however, reflect poorer health as their indicators (e.g. blood pressure, mental health symptoms) are considered poor outcomes.

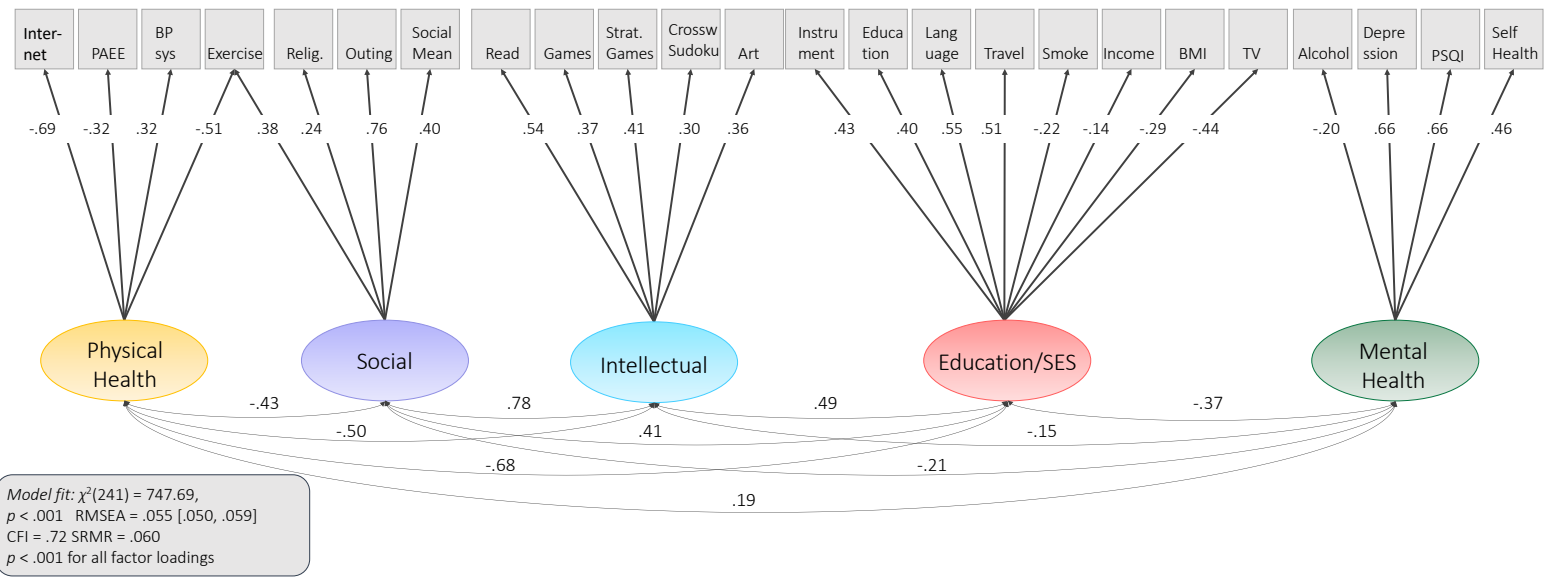

Figure 4. Illustration of the lifestyle CFA. Following the factor loadings obtained via the ESEM, 24 broad lifestyle variables loaded onto five latent lifestyle variables: mental health, social engagement, intellectual engagement, education/SES and physical health. All parameters shown are fully standardized.

\section{Determinants of Healthy Ageing}

Separate regressions

Next, we investigated the extent to which the five lifestyle factors determined our measures of healthy ageing. As the simultaneous estimation of the measurement models (across cognitive and lifestyle domains) and the structural model (regressing cognitive domains on lifestyle variables) could not achieve robust convergence, we used a two-step procedure. First, we extracted the factor scores for both cognitive factors and computed age-adjusted residuals. Second, we regressed measures of fluid and crystallized resilient ageing on the lifestyle factor scores. Doing so, we observed significant associations between each individual lifestyle factor and both fluid and crystallized ageing, as depicted in Figure 5 and Table 3. The 
strongest associations were those between Education/SES and fluid (std $\beta=0.26$ ) and crystallized cognition (std $\beta=0.33$ ), followed by Intellectual Engagement (fluid std $\beta=0.24$, crystallized std $\beta=0.22$ ), Mental Health (fluid std $\beta=-0.17$, crystallized std $\beta=-0.19$ ), Physical Health (fluid std $\beta=-0.17$, crystallized std $\beta=-0.14$ ) and finally Social Engagement (fluid std $\beta$ $=0.15$, crystallized std $\beta=0.10)$. All regressions showed modest deviations of the assumption of homoscedastic residuals (all Breusch-Pagan tests $\chi 2>10, d f=1, p<0.01$ ), with a general increase in variability across the lifespan. To ensure that these heteroscedastic residuals did not affect our inferences concerning lifestyle-cognition associations, we reestimated all models using a heteroscedasticity-consistent robust sandwich estimator (using the package 'sandwich' (47)). As can be seen in Table 3, the parameter estimates and standard errors are virtually identical, suggesting negligible consequences of the heteroscedastic residuals.
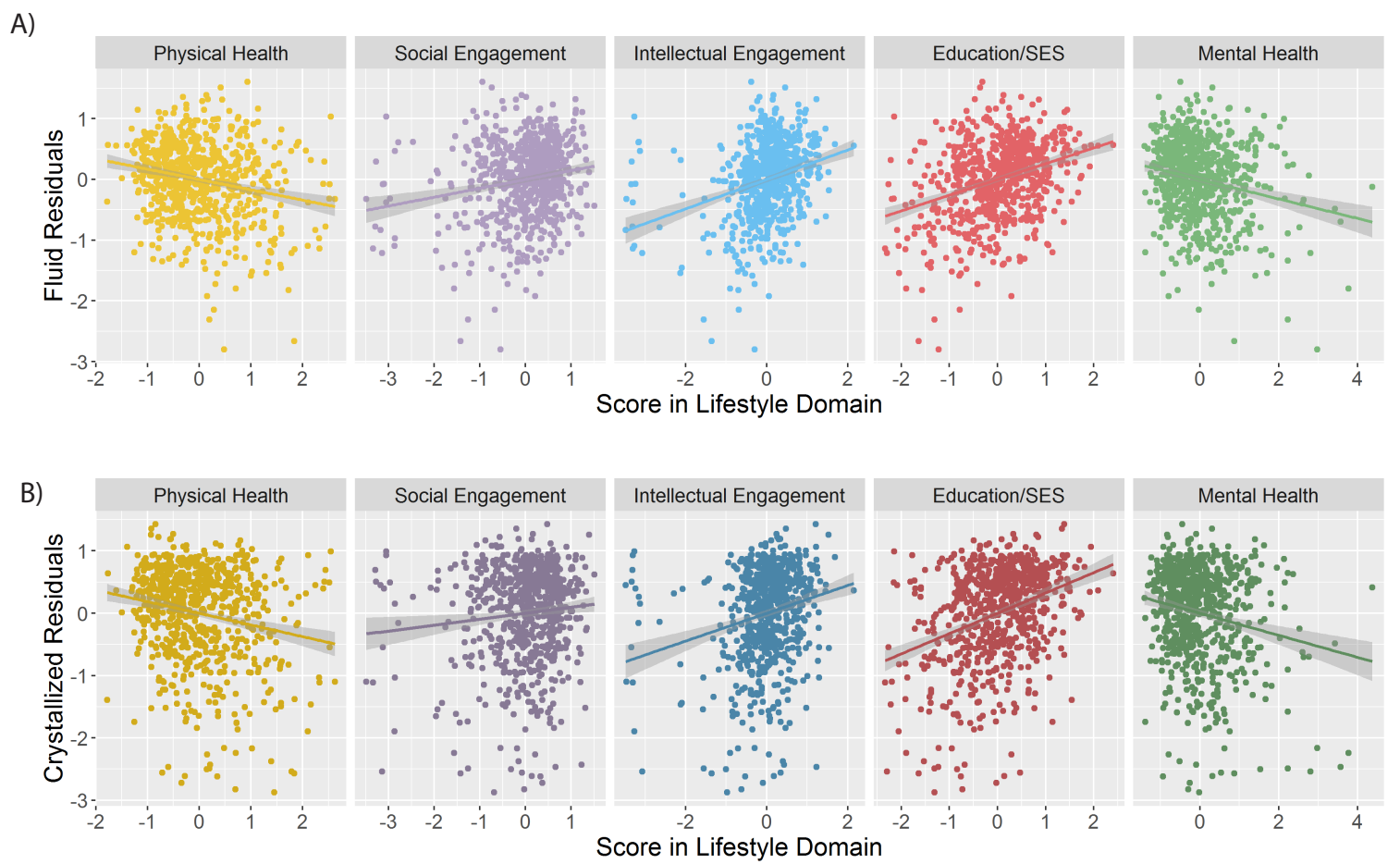

Figure 5. Separate regression results for A) fluid abilities and B) crystallized abilities. All five lifestyle factors were significantly associated with cognitive health across the lifespan. 
Table 3: Separate regression results for fluid and crystallized abilities

\begin{tabular}{|c|c|c|c|c|c|c|c|c|}
\hline $\begin{array}{l}\text { Cognitive } \\
\text { Domain }\end{array}$ & Lifestyle Factor & $\begin{array}{l}\text { Standardized } \\
\text { beta }\end{array}$ & $\begin{array}{l}\text { Standard } \\
\text { Error }\end{array}$ & $p$ & $\mathrm{R}^{2}$ & $\begin{array}{l}\text { Robust } \\
\text { sandwich } \\
\text { beta }\end{array}$ & $\begin{array}{l}\text { Robust } \\
\text { sandwich } \\
\text { SE }\end{array}$ & $p$ \\
\hline \multirow{5}{*}{$\begin{array}{l}\text { Fluid } \\
\text { Abilities }\end{array}$} & Mental Health & -0.16 & 0.03 & $<0.001$ & 0.04 & -0.16 & 0.04 & $<0.001$ \\
\hline & Social & 0.15 & 0.03 & $<0.001$ & 0.03 & 0.15 & 0.03 & $<0.001$ \\
\hline & Intellectual & 0.24 & 0.03 & $<0.001$ & 0.08 & 0.24 & 0.04 & $<0.001$ \\
\hline & Education/SES & 0.26 & 0.03 & $<0.001$ & 0.11 & 0.26 & 0.03 & $<0.001$ \\
\hline & Physical Health & -0.17 & 0.03 & $<0.001$ & 0.05 & -0.17 & 0.03 & $<0.001$ \\
\hline \multirow{5}{*}{$\begin{array}{l}\text { Crystallized } \\
\text { Abilities }\end{array}$} & Mental Health & -0.18 & 0.04 & $<0.001$ & 0.04 & -0.17 & 0.04 & $<0.001$ \\
\hline & Social & 0.10 & 0.03 & $<0.001$ & 0.009 & 0.79 & 0.04 & $<0.001$ \\
\hline & Intellectual & 0.22 & 0.04 & $<0.001$ & 0.05 & 0.22 & 0.04 & $<0.001$ \\
\hline & Education/SES & 0.33 & 0.04 & $<0.001$ & 0.11 & 0.33 & 0.04 & $<0.001$ \\
\hline & Physical Health & -0.19 & 0.04 & $<0.001$ & 0.04 & -0.19 & 0.04 & $<0.001$ \\
\hline
\end{tabular}

Following recent effect size guidelines (48), we interpret the associations between the lifestyle factors and cognition to range from relatively large (Education/SES) to typical (Intellectual Engagement, Mental Health, Physical Health), with small associations found for Social Engagement. In summary, these findings suggest that having higher levels of education/SES as well as physical and mental health, and partaking in intellectually and socially engaging activities, are all individually associated with better fluid and crystallized cognitive outcomes throughout the lifespan, above and beyond age. 


\section{Multiple Regressions}

Next, we examined the joint effects of lifestyle factors on resilient ageing, by simultaneously regressing scores on resilient ageing on all five lifestyle factors (Figure 6). Doing so allowed us to examine the degree to which each of the five lifestyle factors make unique contributions to cognitive resilience. For fluid resilience, Education/SES ( $\operatorname{std} \beta=0.30, \mathrm{SE}=0.06, p<0.001$ ), Social Engagement (std $\beta=-0.12, \mathrm{SE}=0.048, \mathrm{p}=0.012)$, Intellectual Engagement $(\mathrm{std} \beta=$ $0.26, \mathrm{SE}=0.06, p<0.001$ ) and Physical Health (std $\beta=0.20, \mathrm{SE}=0.06, p=0.001$ ), were significant predictors, predicting unique variance in fluid resilience, and together explaining $14 \%$ of the variance. We found a similar pattern for crystallized resilience, with Education/SES $(\operatorname{std} \beta=0.56, \mathrm{SE}=0.075, \mathrm{p}<0.001)$, Social Engagement $(\operatorname{std} \beta=-0.22, \mathrm{SE}=0.059, \mathrm{p}<0.001)$, Intellectual Engagement (std $\beta=0.22, \mathrm{SE}=0.069, \mathrm{p}<0.001$ ) and Physical Health (std $\beta=$ $0.30, \mathrm{SE}=0.07, \mathrm{p}<0.001)$ each significant and together explaining $16 \%$ of the variance. We did not find evidence that mental health made unique contributions to fluid or crystallized resilience beyond the other lifestyle factors.

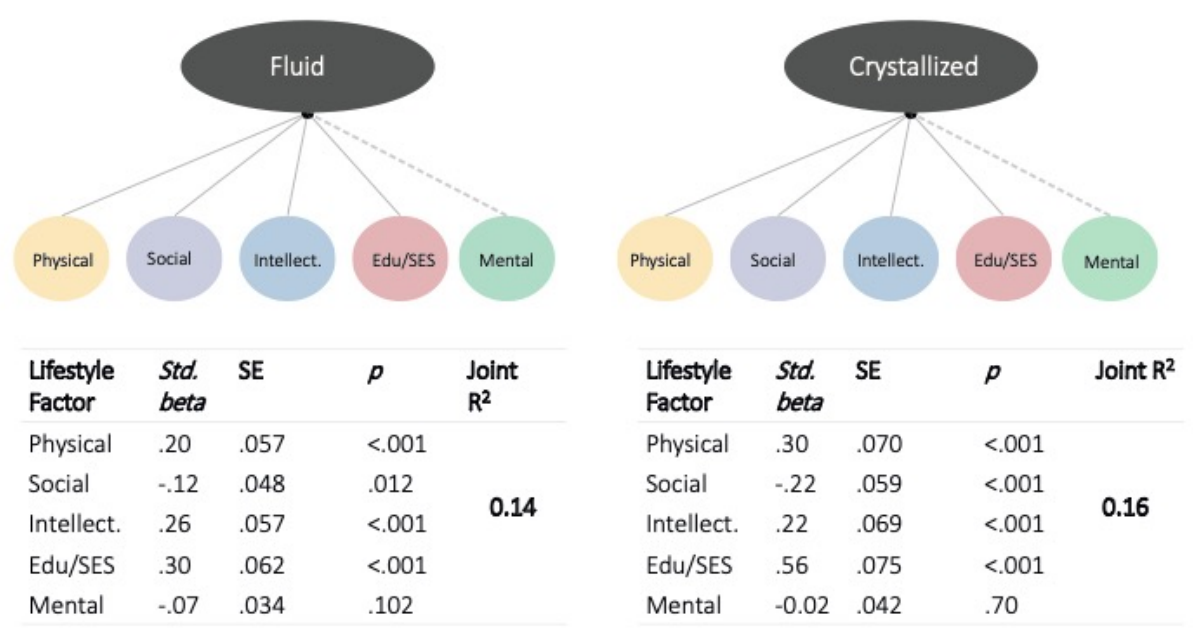

Figure 6. Results of multiple regressions. Four out of five lifestyle factors made unique contributions. 
Notably, in these joint models, the directionality of the effect of Social Engagement changed from positive to negative, while Physical Health changed from negative to positive. These sign inversions may reflect a true conditional association, or rather a quantitative consequence of the dataset and procedure employed here - we discuss these matters in more detail below.

To examine the robustness of this 'reduced' model, we refit the model in a Bayesian model selection framework (43) using Bayesian regression. As before in this cohort (49), we used the default, symmetric Cauchy prior with width of $\frac{\sqrt{2}}{2}$ which translates to a $50 \%$ confidence that the true effect will lie between -0.707 and 0.707 . Doing so yields a Bayes factor for all possible subsets of predictors, thus yielding the model that optimally balances parsimony (excluding unnecessary predictors) with prediction power. In line with the above frequentist model, this comparison (full set of model comparisons shown in supplementary Figure 2) revealed that the best model for both fluid and crystallized abilities included Education/SES, Social Engagement, Intellectual Engagement and Physical Health (but not Mental Health).

Regarding the specificity of the contributing of lifestyle to crystallized versus fluid abilities, we found that the freely estimated model fit marginally better $(\Delta \chi 2(5)=13.92, p=.016)$, suggesting small differences in path estimates. Closer inspection of the parameter estimates showed that this difference was driven almost exclusively by SES, which has a stronger association with crystallized abilities (standardized beta: .56) than with fluid (.38). 


\section{Exploratory Analyses}

Our final set of analyses investigated whether there was evidence for interaction of age or sex with our lifestyle factors: in other words, whether any of the lifestyle factors increase or decrease in importance for cognitive resilience. First, we performed a multi-group model based on a median age split (median = 55 years), which suggested imposing equality constraints across age group did not adversely affect the associations between lifestyle and cognitive outcomes $(\Delta \chi 2(5)=3.799, p=.58)$. Finally, we tested for the presence of sex effects, which again found that the joint model could be equally constrained across sexes without a notable drop in model fit, $\Delta x 2(10)=12.96, p=.23$. This suggests that the beneficial associations between lifestyle and cognitive resilience are similar across age and for both sexes.

\section{Discussion}

\section{Summary of main findings}

In a large lifespan cohort with a broad set of measures, we examined the associations between resilient cognitive ageing and potentially modifiable lifestyle factors. We observed that in isolation, better physical and mental health, increased social and intellectual engagement and higher levels of education/SES were significantly associated with resilient crystallized and fluid cognition (i.e. cognitive abilities higher than those expected for one's age). 
Three out of five lifestyle factors showed typical effect sizes, with Education/SES having a strong, and Social Engagement a small association, respectively (48). Individual lifestyle domains have previously been correlated with cognitive health in old age and our bivariate results provide further evidence for this relationship. However, as described in the introduction, few studies have investigated combinations of lifestyle factors in a way that allows for statistical inferences regarding their complementary effects (e.g., studies that use five separate linear regressions to investigate the associations between cognition and cognitive and social activity, physical activity, diet, alcohol consumption and smoking (6)). Here, when all lifestyle factors were incorporated into the same model, social and intellectual engagement as well as physical health made independent contributions to fluid and crystallized resilience, above and beyond the effect of education/SES. These relationships were robust across age and sex, and highly similar for fluid and crystallized domains, suggesting general effects, rather than effects specific to cognitive domain. Importantly, social, physical and intellectual activities are potentially modifiable. Assuming they are causally related to cognitive resilience, interventions to increase them may help boost the cognitive reserve that appears to support independent functioning in old age.

In both the linear regressions and the joint models, the strongest associations were those between education/SES and cognitive health. This ties in well with the literature: for example, a recent systematic review comprising over 130,000 individuals (19) showed that the relationship between education/SES and healthy ageing was reported in 20 of the 25 included studies. One possible explanation is the notion of cognitive reserve, which suggests that education and occupational attainment are driving the brain's reserve capabilities (50). 
Arguably, however, a person's education or socio-economic status are difficult to alter, particularly later in life. Our finding that physical health and intellectual and social engagement are associated with cognitive health above and beyond education/SES therefore offers further support for the promise that potentially modifiable activities also contribute to cognitive reserve.

Previous studies have also reported beneficial associations between higher level of social engagement and healthy ageing $(4,5,8,51-53)$, consistent with the association found here. Although we find the best solution by positing separate factors for social and intellectual engagement, we note they are relatively highly correlated $(r=.61)$, suggesting a large degree of overlap between the social and intellectual components of lifestyles. Recent work shows a similar overlap: Köhncke and colleagues used the construct of 'leisure activities', which comprised both social and intellectual activities, to examine its impact on longitudinal changes in brain structure and cognitive decline in a large, healthy Swedish cohort (54). Notably, they observed that greater current social activities were associated with more preserved processing speed, and that this effect could be fully explained (mediated) by slower decline of white matter microstructure. Thus, although our study was cross-sectional, it fits well with an increased focus on the benefits of an active socio-intellectual lifestyle in old age. Similarly, recent longitudinal evidence suggests possible reciprocal effects between subjective (self-assessment) and objective (test performance) measures of memory in old age (55). In other words, individuals who think their memory is poor may avoid (social) situations where their memory is challenged, thus accelerating memory decline. It may be that social engagement functions as a method of frequent low-grade cognitive challenge, which helps support cognitive performance in old age. 
One key contribution of this manuscript, echoing recent calls (12), is the simultaneous inclusion of multiple lifestyle factors, in order to better understand their relations and independent contributions. Doing so, we show that four of our five lifestyle factors (all except mental health) contribute uniquely in explaining individual differences in cognitive outcomes. Interestingly, two of the path estimates, namely social and physical, changed sign: While they were, as expected, positively associated with outcomes in isolation, the sign of the association changed in the presence of other, collinear predictors. Both substantive and statistical explanations (which are not mutually exclusive) of these patterns are possible, and we outline both below.

Firstly, we found that social activities became negatively associated with cognitive performance. A possible interpretation is that high levels of social activity which are devoid of intellectual activity may be associated with poorer outcomes. For example, social and intellectual activities may tend to co-occur in people (e.g., frequently meeting with family to play games), but once the intellectual component is accounted for, the remaining types of social activity may actually be detrimental to cognitive ability (e.g., drinking alcohol regularly with friends). Further research using more refined lifestyle measures is needed to address this possibility.

Secondly, in the simple regressions we observed that better physical health was associated with better cognitive outcomes - but this association changed in sign in the full model. The simple association is in line with several other papers, including intervention studies, which have suggested that physical activity reliably reduces the risk of cognitive impairment (56- 
59). However, not all studies observe the same pattern - the UK Whitehall II study found no evidence between physical activity and subsequent 27 year cognitive decline (60), and Gow et al. (14) found that mid-life intellectual and social activities, but not physical activity, were associated with late-life cognitive health (3). Notably, sign reversals need not be counterintuitive. For example, in the same Cam-CAN sample, Fuhrmann et al. observed strong associations such that low diastolic blood pressure (usually associated with lower overall blood pressure) was associated with worse neural health - but only when the model also included systolic blood pressure (61). This pathway thus captured the conditional effect of a large difference between systolic and diastolic blood pressure, known as 'pulse pressure' often associated with (precursors to) diabetes and other medical conditions. Similarly, there may be indirect conditional pathways which substantively explain the sign inversion.

Alternatively, there are more purely quantitative explanations of these sign flips. It is wellknown that high collinearity between predictors (here Intellectual Engagement and Social Engagement $r=.61$; Physical Health and Education/SES $r=.-68$ ) inflates the standard errors of the parameter estimates, which can produce changes in sign of the mean $(62,63)$. However, this increase in standard error would normally render tests on mean no longer significant, which is not the case here (and the standard errors for these paths in the full model were not especially large). More likely is that our findings reflect a type of 'reversal paradox' (64). Yoo and colleagues (2014) discuss three statistical paradoxes that pervade epidemiological research, each of which has important implications for the interpretation of evidence from observational studies. Simpson's paradox, Lord's paradox, and suppression. Although the three statistical paradoxes occur in different types of variables, they share the same characteristic - the association between two variables can be reversed, diminished, or 
enhanced when another variable is statistically controlled for. Understanding the concepts and theory behind these paradoxes provides insights into some controversial or contradictory research findings. These paradoxes show that prior knowledge and underlying causal theory play an important role in the statistical modelling of epidemiological data, where incorrect use of statistical models might produce consistent, replicable, yet erroneous results(64). This phenomenon can occur when parts of a causal chain (i.e. both antecedents and consequences) are incorporated in the same model. This can induce, especially in observational data with correlated predictors, reversals of path estimates depending on the nature of the predictors included. In this light, it is worth considering the 'reverse causation' hypothesis of Kremen et al. (12): They state that many of the protective effects of individual differences in lifestyle factors (such as greater cognitive and social engagements, and even education) are themselves the consequence of early life differences in cognitive ability.

In the absence of direct access to underlying causal mechanisms generating the data, we cannot conclusively say which of the above explanations are most plausible. As such converging lines of evidence from longitudinal studies, interventions and multivariate approaches will be required to understand the true aetiology of these effects. However, it unambiguously demonstrates the importance of simultaneous assessment of multiple lifestyle-cognition associations, if we wish to better understand the complex lifespan process of risk and resilience factors. As has been pointed out elsewhere (65), other suppression and 'reversal paradox' effects can and do - contrary to common criticism - replicate. Our solution here is to we report both the univariate estimates as well as the simultaneous effects 
The effect of mental health, while significant in univariate analyses, disappeared in the joint models. We interpret this as an important null-finding, suggesting that the association between mental health (measured, in this paper, as an emergent latent construct that was measured by depression, quality of sleep, alcohol consumption and self-reported health) and cognitive health is either less strong compared to other lifestyle factors, or fully explained by co-occurrence with other lifestyle factors. This finding differs from those of other crosssectional studies, which found associations between depression and poorer cognitive function in old age (66-68). However, this discrepancy can, in part, be explained by the high degrees of comorbidity between depression and dementia, given that the above studies (unlike the current one) included participants with mild cognitive impairment (MCl) and/or Alzheimer's disease (AD). Indeed, a longitudinal study that employed latent growth models showed that, when participants with $\mathrm{MCl}$ and $\mathrm{AD}$ were removed from the models, the association between cognitive health and depression disappeared (69).

We observed no significant difference of the lifestyle-cognition associations for crystallized compared to fluid resilience; both were captured best by models including education/SES, social engagement and intellectual engagement. We interpret this to suggest that lifestyle is likely to benefit cognition in a global, rather than specific manner. This might have important ramifications for the interpretation of cognitive intervention studies, which often fail to find positive transfer effects. Assessing cognition on latent and global level, rather than by performance on individual tasks might be, as has been suggested elsewhere (70), a more desirable statistical approach. 


\section{Strengths and limitations}

A strength of our analyses is the inclusion of an unusually broad and rich set of lifestyle and cognitive variables in a large lifespan cohort. Uniquely, this allows us to directly compare the relative strength of associations of distinct lifestyle factors within the same healthy population.

The most important limitation of this study is that the data investigated here are crosssectional. For this reason, although our findings align well with other work, we cannot make direct causal inferences regarding the observed associations, as they may be explained by a variety of causal pathways, included omitted third causes. Moreover, as noted above, causality may flow in both directions - better cognitive health may facilitate the desire, as well as capacity, to maintain an active life in old age (8). These issues can be addressed to some extent by longitudinal studies, and most directly by interventional studies. However, it may be all but impossible to engage in a true randomized intervention study of factors as integral to individuals as education, social and intellectual engagement. As such, large observational studies relying on powerful multivariate methodology may offer an imperfect, but nonetheless valuable insight into which lifestyle factors are most likely to have beneficial protective effects in ageing, and therefore provide candidate factors which might be more amenable to intervention studies (as well as advising what other factors should be controlled for in such studies). Moreover, we only examined relationships between current activities and current cognitive abilities: it is possible that many years are needed before lifestyle changes affect cognitive abilities. For example, one's current lifestyle activities in old-age may be of little value if similar beneficial activities were not conducted earlier in life, consistent with our previous findings using retrospective questionnaires, where people's activity scores 
in their current, old age did not make a unique contribution above the same activity scores reported from their previous, mid-life period (34). Further work is needed to more precisely reveal the temporal development of the beneficial effects of lifestyle engagement on cognitive abilities.

Methodologically, our approach comes with strengths and limitations. The use of exploratory structural equation modelling (ESEM) allowed us to categorize the observed variables in a mainly data-driven fashion - an approach that has the potential to decrease researchers' subjectivity and selection bias and improve statistical power. However, our factor extraction approach, aiming for a parsimonious set of factors through ESEM and CFA, has implications for inferences. First, using a data rather than theory-driven approach has the downside of being relatively insensitive to ongoing debates in the literature. For instance, a recent review found little evidence for transfer effects of brain training games and also noted that better evidence is needed assess their efficacy (72). Because this paper's intellectual engagement factor consisted of brain training games (like Computer or Nintendo games) as well as reading, strategic games, Sudoku/Crossword and the degree of engagement in artistic pastime, we are not able to infer the extent to which brain training games alone are positively associated with cognition. As such, the presence of brain training games as part of the intellectual engagement factor reflects a correlation to other variables, rather than a strong claim concerning the effectivity of brain games. For example, our findings are equally compatible with more intellectually-engaged individuals being more likely to seek brain training games, regardless of their effectivity. Second, and as noted before, our factor denoted 'fluid ability' should be considered as a convenient shorthand: This factor reflects a 
broader set of cognitive abilities than more traditional, 'pure' measures of fluid intelligence (e.g. the Cattell test or Raven's matrices, $(73,74))$.

Moreover, certain patterns in the data-driven lifestyle factors may strike some as counterintuitive: For instance, internet use has a strong negative factor loading (-.69) for physical health, such that more internet use is associated with better physical health. We hypothesise that this is a masked age-effect, where younger people (who are generally heathier than older participants) also spend more time using the internet. Relatedly, by grouping lifestyle variables into factors, we decrease the specificity of associations of individual variables, and render the hypothetical translation to intervention targets (i.e. to encourage the increase of purportedly beneficial activities) less straightforward. This reflects a general issue, namely that the assessment of lifestyle-cognition associations warrants a trade-off between generalizability and reduction of measurement error (using latent variables) versus specificity and ease of interpretation (using observed variables). The latter approach has led researchers to conclude, for instance, that knitting, doing odd jobs and gardening all reduce the risk of dementia (75). However, a defence of latent lifestyle factors would posit that such activities are better seen as reflecting a class of activities with similar purported beneficial effects. If there is causal efficacy to, say, knitting, then a coherent causal account would likely posit that activities with similar features (subjective enjoyment, social engagement) would lead to similar beneficial accounts. This line of reasoning is implicitly present in intervention studies that focus on e.g. 'physical activity', 'cardiovascular training' or 'coordination training' (rather than 'walking' or 'using a fitness ball'; e.g., (76)). Additionally, even with individual variables, the notion of modifiability of lifestyle factors is not entirely straightforward, since the behaviours and personality characteristics that are 
amenable to intervention or modification, and the circumstances that enable alterations, have yet to be established. Factors like personality, mood, people's perception of their abilities, as well as more external limitations including mobility and financial security, are all likely to affect the extent to which people alter the various aspects of their lives. Theory- or prediction-based approaches, such as mixture models or decision-tree based methods (77), might provide useful tools to explore these open questions.

Next, although several indicators of model fit are in the acceptable or good range, the CFI is lower than ideal. As the CFI is an index of comparative fit compared to the null model, a lower CFI generally indicates large measurement models with moderate to low factor loadings. Although several of our factor loadings are strong (e.g. social outings on the social factor) others are lower (e.g. alcohol consumption on mental health). This is a consequence of reporting the best fitting exploratory model, which, in a large lifespan observational sample such as Cam-CAN, is likely to group together variables with only moderately strong relations to each other. In contrast, much more well-established measurement models, refined over multiple cohorts, tend to lead to the selection of only indicators with (very) high loadings. As our goal here is explicitly a descriptive, exploratory factor analysis to reduce a rich sample of indicators to a tractable number of lifestyle factors, such a strategy would not be appropriate, both for reasons of generalizability (modifying the factor structure purely for reasons of fit) and principle (we wish to convey the full richness of the data including factor loadings and relationships that perhaps don't fit pre-existing groupings). More importantly, the regressions (both the simultaneous and individual) show moderate to strong effects, suggesting that despite a subset of relatively weak loadings, the factor scores are separable and predictive of external outcomes. As such, we prefer the model as is, with several model 
fit indices that are good but with a less than optimal CFI, rather than us modifying the model to simply achieve a better fit. This reasoning is also in line with our objective to use a data-, as opposed to researcher-driven categorization of variables. While an advantage of modifying the measurement model might be (slightly) better model fit, we believe that the advantages of the data-driven approach (i.e. increased objectivity and greater ease of replicability with other datasets and variables) outweigh these concerns.

Finally, because Cam-CAN represents a sample of healthy adults, the generalizability of our findings to other populations remains to be investigated by future research.

\section{Conclusion}

In conclusion, our findings suggest that lifestyle variables can be grouped into distinct but correlated factors. Moreover, these factors vary in the strength of their associations with cognitive resilience, and make specific, complementary contributions in explaining individual age-related differences. Specifically, we found that education/SES, physical health and social and intellectual engagement, are each simultaneously associated with cognitive resilience across the adult lifespan, and these associations are similar in magnitude and direction for two broad cognitive domains (fluid and crystallized). Mental health, although associated when tested with better cognitive outcomes in isolation, did not make unique contributions above the other three lifestyle factors. Because many of the activities included in our models are, in principle, modifiable, our findings have encouraging implications for individuals and public health initiatives alike. 


\section{Acknowledgements}

The Cambridge Centre for Ageing and Neuroscience (Cam-CAN) research was supported by the Biotechnology and Biological Sciences Research Council (grant number BB/H008217/1). This project has also received funding from the European Union's Horizon 2020 research and innovation programme (grant agreement number 732592). R. A. K. is also supported by the Wellcome Trust (Grant No. 107392/Z/15/Z) and the UK Medical Research Council SUAG/014 RG91365. R.N.A.H. is also supported by the Medical Research Council (SUAG/010 RG91365). We are grateful to the Cam-CAN respondents and their primary care team in Cambridge for their participation in this study.

The Cam-CAN corporate author consists of the project Principal Personnel: Lorraine K Tyler, Carol Brayne, Edward T Bullmore, Andrew C Calder, Rhodri Cusack, Tim Dalgleish, John Duncan, Richard N Henson, Fiona E Matthews, William D Marslen-Wilson, James B Rowe, Meredith A Shafto; Research Associates: Karen Campbell, Teresa Cheung, Simon Davis, Linda Geerligs, Rogier Kievit, Anna McCarrey, Abdur Mustafa, Darren Price, David Samu, Jason R Taylor, Matthias Treder, Kamen Tsvetanov, Janna van Belle, Nitin Williams; Research Assistants: Lauren Bates, Tina Emery, Sharon Erzinclioglu, Andrew Gadie, Sofia Gerbase, Stanimira Georgieva, Claire Hanley, Beth Parkin, David Troy; Affiliated Personnel: Tibor Auer, Marta Correia, Lu Gao, Emma Green, Rafael Henriques; Research Interviewers: Jodie Allen, Gillian Amery, Liana Amunts, Anne Barcroft, Amanda Castle, Cheryl Dias, Jonathan Dowrick, Melissa Fair, Hayley Fisher, Anna Goulding, Adarsh Grewal, Geoff Hale, Andrew Hilton, Frances Johnson, Patricia Johnston, Thea KavanaghWilliamson, Magdalena Kwasniewska, Alison McMinn, Kim Norman, Jessica Penrose, Fiona Roby, Diane Rowland, John Sargeant, 
Maggie Squire, Beth Stevens, Aldabra Stoddart, Cheryl Stone, Tracy Thompson, Ozlem Yazlik; and administrative staff: Dan Barnes, Marie Dixon, Jaya Hillman, Joanne Mitchell, Laura Villis. 


\section{References}

1. Harada CN, Natelson Love MC, Triebel K. Normal Cognitive Aging. Clin Geriatr Med. 2013 Nov;29(4):737-52.

2. Salthouse TA. When does age-related cognitive decline begin? Neurobiology of Aging. 2009 Apr 1;30(4):507-14.

3. Gow AJ, Pattie A, Deary IJ. Lifecourse Activity Participation From Early, Mid, and Later Adulthood as Determinants of Cognitive Aging: The Lothian Birth Cohort 1921. The Journals of Gerontology Series B: Psychological Sciences and Social Sciences. 2017 Jan;72(1):25-37.

4. Small BJ, Dixon RA, McArdle JJ, Grimm KJ. Do changes in lifestyle engagement moderate cognitive decline in normal aging? Evidence from the Victoria Longitudinal Study. Neuropsychology. 2012;26(2):144-55.

5. Lövdén M, Ghisletta P, Lindenberger U. Social Participation Attenuates Decline in Perceptual Speed in Old and Very Old Age. Psychology and Aging. 2005 Sep;20(3):423-34.

6. Clare L, Wu Y-T, Teale JC, MacLeod C, Matthews F, Brayne C, et al. Potentially modifiable lifestyle factors, cognitive reserve, and cognitive function in later life: A cross-sectional study. Miller BL, editor. PLOS Medicine. 2017 Mar 21;14(3):e1002259.

7. Crowe M, Andel R, Pedersen NL, Johansson B, Gatz M. Does Participation in Leisure Activities Lead to Reduced Risk of Alzheimer's Disease? A Prospective Study of Swedish Twins. J Gerontol B Psychol Sci Soc Sci. 2003 Sep 1;58(5):P249-55.

8. Gow AJ, Corley J, Starr JM, Deary IJ. Reverse causation in activity-cognitive ability associations: The Lothian Birth Cohort 1936. Psychology and Aging. 2012 Mar;27(1):250-5.

9. Brown CL, Robitaille A, Zelinski EM, Dixon RA, Hofer SM, Piccinin AM. Cognitive Activity Mediates the Association between Social Activity and Cognitive Performance: A Longitudinal Study. Psychol Aging. 2016 Dec;31(8):831-46.

10. Karp A, Paillard-Borg S, Wang H-X, Silverstein M, Winblad B, Fratiglioni L. Mental, Physical and Social Components in Leisure Activities Equally Contribute to Decrease Dementia Risk. Dementia and Geriatric Cognitive Disorders. 2006;21(2):65-73.

11. Newson RS, Kemps EB. General lifestyle activities as a predictor of current cognition and cognitive change in older adults: a cross-sectional and longitudinal examination. The Journals of Gerontology Series B: Psychological Sciences and Social Sciences. 2005;60(3):P113-P120.

12. Kremen WS, Beck A, Elman JA, Gustavson DE, Reynolds CA, Tu XM, et al. Influence of young adult cognitive ability and additional education on later-life cognition. Proc Natl Acad Sci USA. 2019 Feb 5;116(6):2021-6.

13. Cattell RB. The measurement of adult intelligence. Psychological Bulletin. 1943 Mar;40(3):15393. 
14. Gottfredson LS, Deary IJ. Intelligence Predicts Health and Longevity, but Why? Current Directions in Psychological Science. 2004;13(1):1-4.

15. Schaie KW. The course of adult intellectual development. American Psychologist. 1994 Apr;49(4):304-13.

16. Tucker-Drob EM. Global and Domain-Specific Changes in Cognition throughout Adulthood. Dev Psychol. 2011 Mar;47(2):331-43.

17. Horn JL, Cattell RB. Age differences in fluid and crystallized intelligence. Acta Psychologica. 1967 Jan 1;26:107-29.

18. Verhaeghen P. Aging and vocabulary scores: a meta-analysis. Psychol Aging. 2003 Jun;18(2):332-9.

19. Kralj C, Daskalopoulou C, Rodriguez-Artalejo F, Garcia-Esquinas E. Healthy ageing: a systematic review of risk factors - Athlos Project. 2018; Available from: http://athlosproject.eu/healthyageing-a-systematic-review-of-risk-factors/

20. Lin FV, Wang X, Wu R, Rebok GW, Chapman BP, Initiative the ADN. Identification of Successful Cognitive Aging in the Alzheimer's Disease Neuroimaging Initiative Study. Journal of Alzheimer's Disease. 2017 Jan 1;59(1):101-11.

21. Gefen T, Shaw E, Whitney K, Martersteck A, Stratton J, Rademaker A, et al. Longitudinal Neuropsychological Performance of Cognitive SuperAgers. J Am Geriatr Soc. 2014 Aug;62(8):1598-600.

22. Rogalski EJ, Gefen T, Shi J, Samimi M, Bigio E, Weintraub S, et al. Youthful Memory Capacity in Old Brains: Anatomic and Genetic Clues from the Northwestern SuperAging Project. J Cogn Neurosci. 2013 Jan;25(1):29-36.

23. Harrison TM, Weintraub S, Mesulam M-M, Rogalski E. Superior Memory and Higher Cortical Volumes in Unusually Successful Cognitive Aging. Journal of the International Neuropsychological Society. 2012 Nov;18(06):1081-5.

24. Sun FW, Stepanovic MR, Andreano J, Barrett LF, Touroutoglou A, Dickerson BC. Youthful brains in older adults: Preserved neuroanatomy in the default mode and salience networks contributes to youthful memory in superaging. Journal of Neuroscience. 2016;36(37):96599668.

25. McClelland GH, Lynch, JG, Irwin JR, Spiller SA, Fitzsimons GJ. Median splits, Type II errors, and false-positive consumer psychology: Don't fight the power. Journal of Consumer Psychology. 2015 Oct;25(4):679-89.

26. Raz N, Lindenberger U. Only Time will Tell: Cross-sectional Studies Offer no Solution to the AgeBrain-Cognition Triangle-Comment on. Psychol Bull. 2011 Sep;137(5):790-5.

27. Shafto MA, Tyler LK, Dixon M, Taylor JR, Rowe JB, Cusack R, et al. The Cambridge Centre for Ageing and Neuroscience (Cam-CAN) study protocol: a cross-sectional, lifespan, multidisciplinary examination of healthy cognitive ageing. BMC Neurology. 2014 Oct 14;14:204.

28. Taylor JR, Williams N, Cusack R, Auer T, Shafto MA, Dixon M, et al. The Cambridge Centre for Ageing and Neuroscience (Cam-CAN) data repository: Structural and functional MRI, MEG, and 
cognitive data from a cross-sectional adult lifespan sample. Neurolmage. 2017 Jan 1;144:2629.

29. Folstein MF, Folstein SE, McHugh PR. "Mini-mental state". A practical method for grading the cognitive state of patients for the clinician. J Psychiatr Res. 1975 Nov;12(3):189-98.

30. Snellen H. Probebuchstaben zur Bestimmung der Sehschärfe. Utrecht: Van de Weijer. 1862;

31. Zigmond AS, Snaith RP. The hospital anxiety and depression scale. Acta Psychiatr Scand. 1983 Jun;67(6):361-70.

32. Buysse DJ, Reynolds CF, Monk TH, Berman SR, Kupfer DJ. The Pittsburgh sleep quality index: A new instrument for psychiatric practice and research. Psychiatry Research. 1989 May;28(2):193-213.

33. Valenzuela MJ, Sachdev P. Assessment of complex mental activity across the lifespan: development of the Lifetime of Experiences Questionnaire (LEQ). Psychological Medicine. 2007 Jul;37(07):1015.

34. Chan D, Shafto $M$, Kievit $R$, Matthews $F$, Spink $M$, Valenzuela $M$, et al. Lifestyle activities in midlife contribute to cognitive reserve in late-life, independent of education, occupation and latelife activities. bioRxiv. 2018 Feb 19;267831.

35. Asparouhov T, Muthén B. Exploratory Structural Equation Modeling. Structural Equation Modeling: A Multidisciplinary Journal. 2009 Jul 14;16(3):397-438.

36. Revelle W. Procedures for psychological, psychometric, and personality research, version 1.8 .3 [Internet]. Northwestern University, Evanston, IL; 2018. Available from: https://CRAN.Rproject.org/package=psych

37. Cole JH, Franke K. Predicting Age Using Neuroimaging: Innovative Brain Ageing Biomarkers. Trends in Neurosciences. 2017 Dec;40(12):681-90.

38. van Harmelen A-L, Kievit RA, loannidis K, Neufeld S, Jones PB, Bullmore E, et al. Adolescent friendships predict later resilient functioning across psychosocial domains in a healthy community cohort. Psychol Med. 2017 Oct;47(13):2312-22.

39. Devlieger I, Rosseel Y. Factor score path analysis: An alternative for SEM? Methodology: European Journal of Research Methods for the Behavioral and Social Sciences. 2017;13(Suppl 1):31-8.

40. Rosseel Y. The lavaan tutorial. Department of Data Analysis: Ghent University [Internet]. 2014 [cited 2017 Jul 10]; Available from: http://dornsifecms.usc.edu/assets/sites/210/docs/GC3/lavaan_tutorial.pdf

41. Enders CK, Bandalos DL. The Relative Performance of Full Information Maximum Likelihood Estimation for Missing Data in Structural Equation Models. Structural Equation Modeling: A Multidisciplinary Journal. 2001 Jul 1;8(3):430-57.

42. Schermelleh-Engel K, Moosbrugger H, Müller H. Evaluating the Fit of Structural Equation Models: Tests of Significance and Descriptive Goodness-of-Fit Measures. Methods of Psychological Research. 2003;8(2):23-74. 
43. Rouder JN, Morey RD. Default Bayes Factors for Model Selection in Regression. Multivariate Behavioral Research. 2012 Nov 1;47(6):877-903.

44. Ghisletta $P$, Rabbitt $P$, Lunn $M$, Lindenberger $U$. Two thirds of the age-based changes in fluid and crystallized intelligence, perceptual speed, and memory in adulthood are shared. Intelligence. 2012;40(3):260-8.

45. Rönnlund M, Nilsson L-G. Adult life-span patterns in WAIS-R Block Design performance: Crosssectional versus longitudinal age gradients and relations to demographic factors. Intelligence. 2006 Jan;34(1):63-78.

46. Baltes PB, Cornelius SW, Spiro A, Nesselroade JR, Willis SL. Integration versus differentiation of fluid/crytallized intelligence in old age. Developmental Psychology. 1980;16(6):625-35.

47. Zeileis A. Econometric Computing with $\mathrm{HC}$ and $\mathrm{HAC}$ Covariance Matrix Estimators. Journal of Statistical Software. 2004 Nov 29;11(1):1-17.

48. Gignac GE, Szodorai ET. Effect size guidelines for individual differences researchers. Personality and Individual Differences. 2016 Nov;102:74-8.

49. Gadie A, Shafto M, Leng Y, Cam-CAN, Kievit RA. How are age-related differences in sleep quality associated with health outcomes? An epidemiological investigation in a UK cohort of 2406 adults. BMJ Open. 2017 Aug 1;7(7):e014920.

50. Stern Y. What is cognitive reserve? Theory and research application of the reserve concept. Journal of the International Neuropsychological Society. 2002 Mar;8(3):448-60.

51. Andrews G, Clark M, Luszcz M. Successful Aging in the Australian Longitudinal Study of Aging: Applying the MacArthur Model Cross-Nationally. Journal of Social Issues. 58(4):749-65.

52. Pruchno RA, Wilson-Genderson M. A Longitudinal Examination of the Effects of Early Influences and Midlife Characteristics on Successful Aging. J Gerontol B Psychol Sci Soc Sci. 2015 Nov 1;70(6):850-9.

53. Zaslavsky O, Cochrane BB, Woods NF, LaCroix AZ, Liu J, Herting JR, et al. Trajectories of positive aging: observations from the women's health initiative study. International Psychogeriatrics. 2014 Aug;26(08):1351-62.

54. Köhncke Y, Laukka EJ, Brehmer Y, Kalpouzos G, Li T-Q, Fratiglioni L, et al. Three-year changes in leisure activities are associated with concurrent changes in white matter microstructure and perceptual speed in individuals aged 80 years and older. Neurobiology of Aging. 2016 May;41:173-86.

55. Snitz BE, Small BJ, Wang T, Chang C-CH, Hughes TF, Ganguli M. Do Subjective Memory Complaints Lead or Follow Objective Cognitive Change? A Five-Year Population Study of Temporal Influence. Journal of the International Neuropsychological Society. 2015 Oct;21(09):732-42.

56. Colcombe S, Kramer AF. Fitness Effects on the Cognitive Function of Older Adults: A MetaAnalytic Study. Psychological Science. 2003;14(2):125-30.

57. Gill SJ, Friedenreich CM, Sajobi TT, Longman RS, Drogos LL, Davenport MH, et al. Association between Lifetime Physical Activity and Cognitive Functioning in Middle-Aged and Older 
Community Dwelling Adults: Results from the Brain in Motion Study. Journal of the International Neuropsychological Society. 2015 Nov;21(10):816-30.

58. Kramer AF, Erickson $\mathrm{KI}$, Colcombe SJ. Exercise, cognition, and the aging brain. Journal of Applied Physiology. 2006 Oct 1;101(4):1237-42.

59. Middleton LE, Barnes DE, Lui L-Y, Yaffe K. Physical Activity Over the Life Course and its Association with Cognitive Performance and Impairment in Old Age. J Am Geriatr Soc. 2010 Jul;58(7):1322-6.

60. Sabia S, Dugravot A, Dartigues J-F, Abell J, Elbaz A, Kivimäki M, et al. Physical activity, cognitive decline, and risk of dementia: 28 year follow-up of Whitehall II cohort study. BMJ. 2017 Jun 22;357:j2709.

61. Fuhrmann D, Nesbitt D, Shafto M, Rowe JB, Price D, Gadie A, et al. Strong and specific associations between cardiovascular risk factors and white matter micro- and macrostructure in healthy aging. Neurobiol Aging. 2019 Feb;74:46-55.

62. Yoo W, Mayberry R, Bae S, Singh K, (Peter) He Q, Lillard JW. A Study of Effects of MultiCollinearity in the Multivariable Analysis. Int J Appl Sci Technol. 2014 Oct;4(5):9-19.

63. Goldberger AS, Goldberger G Arthur Stanley. A Course in Econometrics. Harvard University Press; 1991.430 p.

64. Tu Y-K, Gunnell D, Gilthorpe MS. Simpson's Paradox, Lord's Paradox, and Suppression Effects are the same phenomenon - the reversal paradox. Emerging Themes in Epidemiology. 2008 Jan 22;5(1):2.

65. Paulhus DL, Robins RW, Trzesniewski KH, Tracy JL. Two Replicable Suppressor Situations in Personality Research. Multivariate Behavioral Research. 2004 Apr;39(2):303-28.

66. Bunce D, Tzur M, Ramchurn A, Gain F, Bond FW. Mental Health and Cognitive Function in Adults Aged 18 to 92 Years. J Gerontol B Psychol Sci Soc Sci. 2008 Mar 1;63(2):P67-74.

67. Elderkin-Thompson V, Mintz J, Haroon E, Lavretsky H, Kumar A. Executive dysfunction and memory in older patients with major and minor depression. Archives of Clinical Neuropsychology. 2007 Feb 1;22(2):261-70.

68. Reppermund S, Brodaty H, Crawford JD, Kochan NA, Slavin MJ, Trollor JN, et al. The relationship of current depressive symptoms and past depression with cognitive impairment and instrumental activities of daily living in an elderly population: The Sydney Memory and Ageing Study. Journal of Psychiatric Research. 2011 Dec 1;45(12):1600-7.

69. Bunce D, Batterham PJ, Mackinnon AJ, Christensen H. Depression, anxiety and cognition in community-dwelling adults aged 70 years and over. Journal of Psychiatric Research. 2012 Dec;46(12):1662-6.

70. Schmiedek F, Lövdén M, Lindenberger U. Hundred Days of Cognitive Training Enhance Broad Cognitive Abilities in Adulthood: Findings from the COGITO Study. Front Aging Neurosci [Internet]. 2010 [cited 2018 May 16];2. Available from: https://www.frontiersin.org/articles/10.3389/fnagi.2010.00027/full 
71. Dr C Kralj, Ms C Daskalopoulou, Professor F Rodríguez-Artalejo, Dr E García-Esquinas, Dr TD Cosco, Professor M Prince, Dr AM Prina on behalf of the ATHLOS consortium. Healthy ageing: a systematic review of risk factors - Athlos Project [Internet]. 2018 [cited 2018 Jul 11]. Available from: http://athlosproject.eu/healthy-ageing-a-systematic-review-of-risk-factors/

72. Simons DJ, Boot WR, Charness N, Gathercole SE, Chabris CF, Hambrick DZ, et al. Do "BrainTraining" Programs Work? Psychological Science in the Public Interest. 2016 Oct;17(3):103-86.

73. Cattell RB, Cattell AKS. Measuring Intelligence with the Culture Fair Tests. Institute for Personality and Ability Testing. 1960;

74. Hertzog C, Kramer AF, Wilson RS, Lindenberger U. Enrichment Effects on Adult Cognitive Development: Can the Functional Capacity of Older Adults Be Preserved and Enhanced? Psychol Sci Public Interest. 2008 Oct 1;9(1):1-65.

75. Fabrigoule C, Letenneur L, Dartigues JF, Zarrouk M, Commenges D, Barberger-Gateau P. Social and leisure activities and risk of dementia: a prospective longitudinal study. J Am Geriatr Soc. 1995 May;43(5):485-90.

76. Voelcker-Rehage C, Godde B, Staudinger UM. Cardiovascular and Coordination Training Differentially Improve Cognitive Performance and Neural Processing in Older Adults. Front Hum Neurosci [Internet]. 2011 Mar 17 [cited 2018 Oct 2];5. Available from: https://www.ncbi.nlm.nih.gov/pmc/articles/PMC3062100/

77. Brandmaier AM, Prindle JJ, McArdle JJ, Lindenberger U. Theory-guided exploration with structural equation model forests. Psychological Methods. 2016;21(4):566-82.

78. Shallice T, Burgess PW. Deficits in strategy application following frontal lobe damage in man. Brain. 1991 Apr;114 ( Pt 2):727-41.

79. Baddeley A, Emslie H, Nimmo-Smith I. The Spot-the-Word test: A robust estimate of verbal intelligence based on lexical decision. British Journal of Clinical Psychology. 1993 Feb 1;32(1):55-65.

80. Rodd JM, Longe OA, Randall B, Tyler LK. The functional organisation of the fronto-temporal language system: Evidence from syntactic and semantic ambiguity. Neuropsychologia. 2010 Apr 1;48(5):1324-35.

81. Clarke A, Taylor KI, Devereux B, Randall B, Tyler LK. From Perception to Conception: How Meaningful Objects Are Processed over Time. Cereb Cortex. 2013 Jan 1;23(1):187-97.

82. Lezak, Muriel, Deutsch. Neuropsychological assessment. Oxford University Press; 1995.

83. Hodges J. Neurological aspects of dementia and normal aging. Dementia and Normal Aging Cambridge University Pres. 1994;

84. Benton AL. Contributions to Neuropsychological Assessment: A Clinical Manual. Oxford University Press; 1994. 178 p.

85. Ekman P, Friesen WV. Pictures of facial affect. Consulting Psychologists Press. 1976;

86. Zhang W, Luck SJ. Discrete fixed-resolution representations in visual working memory. Nature. 2008 May;453(7192):233-5. 
87. Wechsler CJ. Wechsler Memory Scale, Third UK Edition. London: Harcourt Assessment; 1999. 